\title{
Frutos y semillas de árboles tropicales de México
}

Jorge Rodriguez Vebazquez, Praxedis Sinaca Colin y Gilberto Jamangapé Garcia

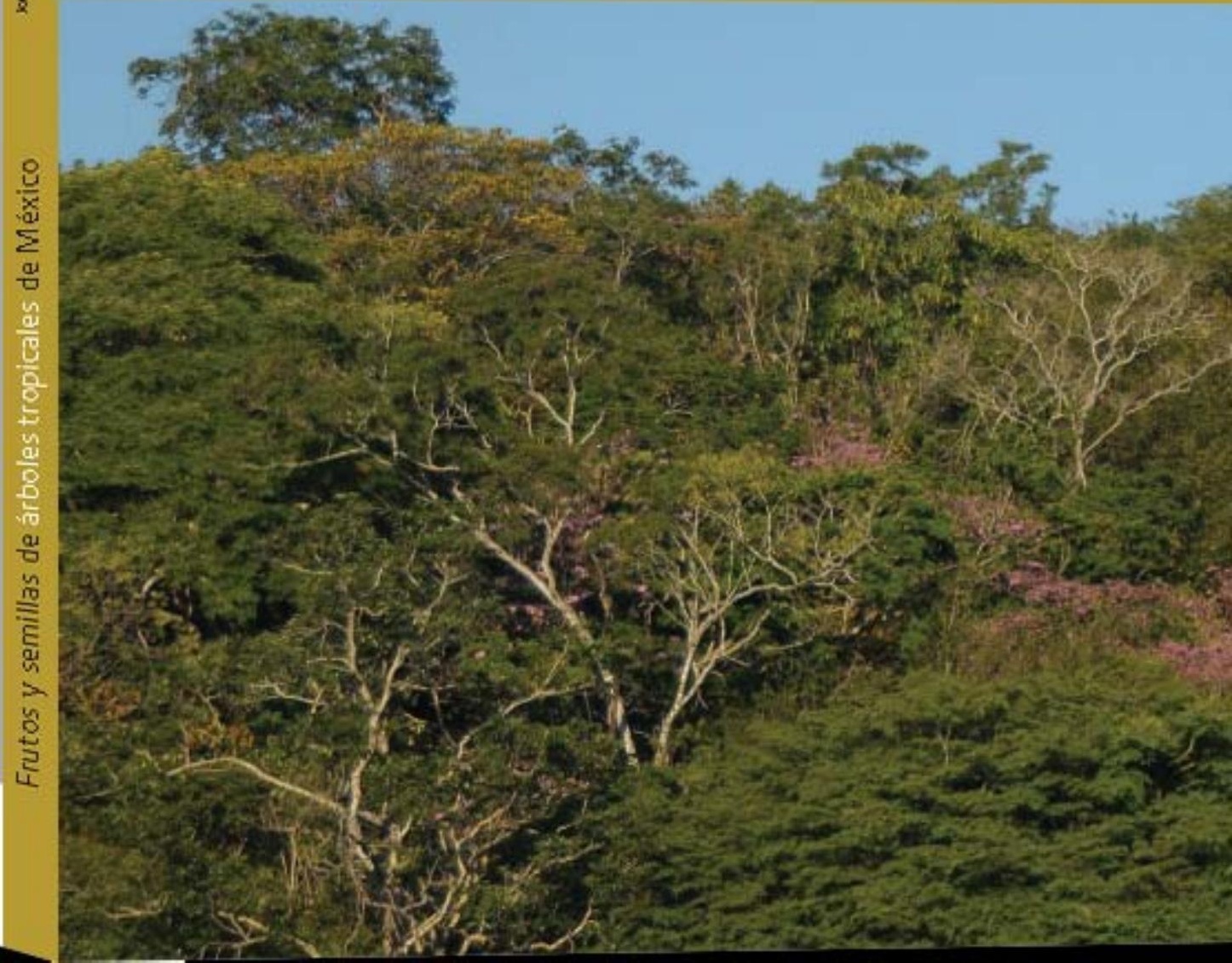




\section{Frutos y semillas de árboles tropicales de México}

Jorge Rodríguez Velázquez

Praxedis Sinaca Colín Gilberto Jamangapé García 
D.R. () Primera edición: marzo de 2009

Secretaría de Medio Ambiente y Recursos Naturales (SEmARnAT)

Blvd. Adolfo Ruiz Cortines 4209. Col. Jardines de la Montaña

C.P. 14210. Delegación Tlalpan, México, D.F.

www.semarnat.gob.mx

Instituto Nacional de Ecología (INE-Semarnat)

Periférico sur 5000, colonia Insurgentes Cuicuilco,

C.P. 04530. México, D.F.

www.ine.gob.mx

Diseño PORTADA E INTERIORES: Álvaro Figueroa

Foto de LA PORTADA: Claudio Contreras Koob

Edición PARA InTERnet: Susana Escobar Maravillas 


\section{Frutos y semillas de árboles tropicales de México}

Jorge Rodríguez Velázquez

Praxedis Sinaca Colín

Gilberto Jamangapé García 


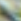




\section{ÍNDICE}

Prólogo 9

$\begin{array}{ll}\text { Introducción } & 12\end{array}$

$\begin{array}{ll}\text { Agradecimientos } & 14\end{array}$

Mosquitoxylum jamaicense $\quad 13$

Spondias radlkoferi 14

Cymbopetalum baillonii 15

Rollinia jimenezii 16

$\begin{array}{ll}\text { Aspidosperma megalocarpo } & 17\end{array}$

Stemmadenia donnell-smithii 18

$\begin{array}{ll}\text { Tabernaemontana alba } & 19\end{array}$

Dendropanax arboreus 20

Amphitecna tuxtlensis 21

Tabebuia rosea $\quad 22$

Parmentiera aculeata $\quad 23$

Bernoullia flammea 24

Ceiba pentandra 25

Ochroma pyramidale $\quad 26$

$\begin{array}{ll}\text { Pachira aquatica } & 27\end{array}$

Cordia alliodora 28

Cordia diversifolia 29

Cordia megalantha 30

Rochefortia lundellii 31

Bursera simaruba $\quad 32$

Protium copal 33

Carica papaya $\quad 34$

Capparis mollicella Standl. 
Cecropia obtusifolia

Hirtella triandra

Licania platypus

Cochlospermum vitifolium

Terminalia amazonia

Diospyros digyna

Muntingia calabura

Erythroxylum tabascense

Adelia barbinervis

Croton schiedeanus

Omphalea oleifera

Pleuranthodendron lindenii

Zuelania guidonia

Calophyllum brasiliense

Rheedia edulis

Calatola laevigata

Nectandra ambigens

Nectandra reticulata

Acacia cornigera

54

Albizia leucocalyx

55

Albizia purpusii

56

Andira galeottiana

57

Cojoba arborea

58

Cynometra retusa

Dialium guianense

Enterolobium cyclocarpum

Erythrina folkersii

Gliricidia sepium

Hymenaea courbaril

Inga pavoniana 
Lonchocarpus rugosus

Platymiscium yucatanum 69

Pterocarpus rohrii $\quad 70$

Schizolobium parahyba 71

Swartzia guatemalensis $\quad 72$

Vatairea lundellii 73

Talauma mexicana 74

Hampea nutricia $\quad 75$

Robinsonella mirandae $\quad 76$

Bellucia grossularioides $\quad 77$

Miconia argentea $\quad 78$

Cedrela odorata $\quad 79$

Guarea glabra 80

Guarea grandifolia 81

Swietenia macrophylla $\quad 82$

Trichilia havanensis 83

Brosimum alicastrum 84

Castilla elastica 85

Ficus maxima $\quad 86$

$\begin{array}{ll}\text { Poulsenia armata } & 87\end{array}$

Trophis mexicana $\quad 88$

Virola guatemalensis $\quad 89$

Eugenia acapulcensis 90

Pimienta dioica 91

Coccoloba hondurensis 92

Calycophyllum candidissimum 93

Faramea occidentalis 94

Posoqueria latifolia $\quad 95$

Psychotria simiarum 96

Zanthoxylum caribaeum $\quad 97$

Cupania glabra 98

Cupania macrophylla 99 
Sapindus saponaria

Pouteria campechiana

101

Pouteria sapota

102

Guazuma ulmifolia

103

Heliocarpus appendiculatus

104

Luehea speciosa

105

Mortoniodendron guatemalense

106

Trichospermum mexicanum

107

Ampelocera hottlei

108

Trema micrantha

109

Aegiphila costaricensis

110

Citharexylum affine

111

Vochysia guatemalensis

112

Glosario

113

Bibliografía 


\section{PRÓLOGO}

Un VIEJO, PERO SABIO REFRÁn, dice que no se puede cuidar lo que no se conoce y nuestro país a lo largo de su historia se ha ocupado de confirmar el dicho. Tras siglos de una relación muy íntima con la naturaleza que los rodeaba (tanto que en ello les iba frecuentemente la sobrevivencia- a los muchos grupos étnicos del país), enfrentamos en México, con la conquista, la imposición de una cultura sobre la naturaleza, ajena del todo a la existente en nuestro territorio; una cultura que, en una mezcla de soberbia e ignorancia, desechó el conocimiento nativo y todo lo que éste representaba en riqueza de comprensión de la naturaleza. Tres siglos de este proceso fueron suficientes no sólo para avasallar a ese conocimiento, sino para dejar establecido en gran parte de la sociedad mexicana, que tenía dominio de lo que se hacía y lo que pasaba, una incultura muy extendida sobre la naturaleza de este país, incultura que ha logrado perdurar hasta el presente. Paradójicamente, España -como casi todos los países 
europeos- posee y estimula en la actualidad entre los miembros de su sociedad un amplio conocimiento de su naturaleza, por medio de excelentes publicaciones y otros medios audiovisuales.

En México hemos avanzado en este sentido, aunque modestamente, en las últimas tres o cuatro décadas con la publicación de un creciente número de libros y otras publicaciones sobre la naturaleza mexicana, diseñadas para ilustrar a un público general la gran riqueza de nuestro patrimonio natural, su enorme valor para nuestra sobrevivencia $y$, por qué no, también la sorprendente belleza de formas, colores y adaptaciones de los organismos.

El presente libro es una muy buena contribución en este sentido. Escrito por quienes conocen de primera mano el contenido del mismo, ilustra de estupenda forma y con fotografías de buena calidad, alrededor de un centenar de especies tropicales, la mayoría presente en la región de Los Tuxtlas, Veracruz, en donde los autores han trabajado por años y de la que uno de ellos es, además, nativo.

Esta obra complementa de manera muy efectiva y útil -con la ilustración y descripción de frutos y semillas- otras que se han publicado o reeditado recientemente, sobre temas muy cercanos. Es una gran ayuda en el proceso de estudiar y conocer la naturaleza del país para identificar los árboles más importantes de la zona tropical, cuyos especimenes frecuentemente alcanzan tales alturas en el dosel de la selva que resulta no sólo imposible obtener una muestra de una rama y hojas, sino incluso a veces distinguir la copa del árbol desde el suelo. La posibilidad de tener una guía ilustrada con fotografías excelentes que ayude a reconocer los frutos y las semillas que se encuentran en el suelo, o a verificar la identificación de un espécimen que se ha recolectado con material fértil, facilita el trabajo de campo. 
El mejor rédito para los esfuerzos de quienes han producido este tipo de guías de campo, es su utilización intensa y el beneficio de quienes al usarlas aplican su conocimiento a entender mejor nuestro recursos naturales y a ayudar, aunque sea en medida modesta, a preservarlos y manejarlos de manera más racional. Las instituciones mexicanas en cuyo seno se cultiva este tipo de trabajo académico debieran estimular la producción de estos materiales y a difundirlos de la manera más amplia entre el público potencialmente interesado.

No puede uno sino desear que muchos más amantes de la naturaleza mexicana, ya sean profesionistas entrenados o, más notablemente, ciudadanos profundamente interesados y atraídos por la belleza inigualable de nuestra flora y faunas, así como de los ecosistemas que contienen a esas especies, se decidan a escribir más de este excelente tipo de guías de campo. Bienvenidos estos esfuerzos que ayudan a impulsar la cultura del conocimiento de nuestra naturaleza entre los mexicanos.

José Sarukhán

Investigador emérito del Instituto de Ecología de la UNAM y Coordinador Nacional de la Comisión Nacional para el Conocimiento y Uso de la Biodiversidad de México (CONABIO) 


\section{INTRODUCCIÓN}

ESTE LIBRo tiene el propósito de dar a conocer al público en general, una pequeña muestra de la gran diversidad de formas y colores de frutos y semillas de árboles tropicales de México. También tiene el propósito de ayudar a estudiantes, así como a profesionistas a identificar de manera rápida y sencilla por medio de la fotografía, frutos y semillas de algunos árboles tropicales.

El libro contiene casi un centenar de fotografías de frutos y semillas de diferentes especies de árboles tropicales. Cada una de las imágenes está acompañada de información importante como: la familia, el género, el nombre común y científico, la descripción de la semilla y del fruto, el periodo de fructificación, el síndrome de dispersión y la distribución general que tienen cada especie en México. Para mostrar detalles importantes de la semilla y del fruto, se tomó más de una fotografía y se aumentó su tamaño.

La distribución de cada especie en este libro está sustentada por listados florísticos de los estados de: Veracruz, Tabasco, Chiapas, Quintana Roo, Campeche, Chetumal, Isla Cozumel, Jalisco, Oaxaca y Nayarit. De informes y programas de manejo y conservación de diferentes estados de la republica. Como partede la labor de investigación se colectaron de semillas y frutos en los estados de Chiapas y Veracruz, las cuales se encuentran en el Centro de Investigaciones en Ecosistemas (CIECO) de la UNAM, campus Morelia, Michoacán. También se consultaron las colecciones de semillas del Herbario Nacional (MEXU) en la estación de Biología Tropical de 
Los Tuxtlas, Veracruz y las que tiene el Laboratorio de Poblaciones y Comunidades Tropicales del CIECO, UNAM.

Para algunas especies se tomó la fotografía del "hueso", que comprende la semilla cubierta por un endospermo duro, y que permite identificar algunas especies de árboles en el campo. Esta es la razón para que en algunos casos aparezca la foto de esta parte de la planta y no de la semilla.

Se optó por ordenar la exposición siguiendo el orden orden alfabético por familia, género y especie. El paréntesis que se encuentra después de la familia Leguminosae, indica la subfamilia a que pertenece. Cada ficha incluye el nombre común con el que se conoce cada especie, una descripción del fruto y la semilla, su periodo de fructificación, la forma de dispersión y los estados o regiones donde se distribuyen. 


\section{AGRADECIMIENTOS}

Acradecemos al Instituto Nacional de Ecología (INE) por el apoyo brindado a este proyecto, especialmente a Eduardo Peters, Ernesto Vega, Gloria Portales Betancourt, y Roberto Márquez. A la estación de Biología Tropical "Los Tuxtlas", Veracruz. Al Herbario Nacional de México (MEXU), al Centro de Investigaciones en Ecosistemas de la UNAM, por facilitarnos el trabajo. También al I.S.C. Heberto Ferreira y al biol. Raúl Ahedo por el apoyo técnico para la realización de este libro. De manera especial queremos agradecer al Dr. Jerzy Rzedowski por su revisión y sugerencias, al Dr. José Sarukhán quien amablemente aceptó escribir el prólogo, al Dr. Miguel Martínez Ramos, por su apoyo en el laboratorio de Poblaciones y Comunidades Tropicales, al Dr. Sergio Zárate por facilitarnos los datos y las semillas de la especie Leucaena macrophylla y por sus comentarios al manuscrito. También queremos darle las gracias al M.C. Oscar Chávez por sus datos sobre el tipo de dispersión que tienen algunos frutos y por facilitar la fotografía de Acacia cornigera. Por último, queremos reconocer con afecto a nuestras familias su apoyo y comprensión. 


\section{Mosquitoxylum jamaicense Krug \& Urban. Anacardiaceae}

Nombre común: en Chiapas: paljulté. Fruto y semilla: drupa roja de olor fragante de forma obovoide. Mide $1 \mathrm{~cm}$ de largo por $0.8 \mathrm{~cm}$ de diámetro; contiene una semilla de color amarillento que mide 0.8 $\mathrm{cm}$ de largo por $0.6 \mathrm{~cm}$ de diámetro.

Fructificación: de julio a septiembre.

Síndrome de dispersión: zoocoria.

Distribución: Veracruz, Tabasco, Oaxaca, Chiapas, Chetumal, Quintana Roo y Campeche.

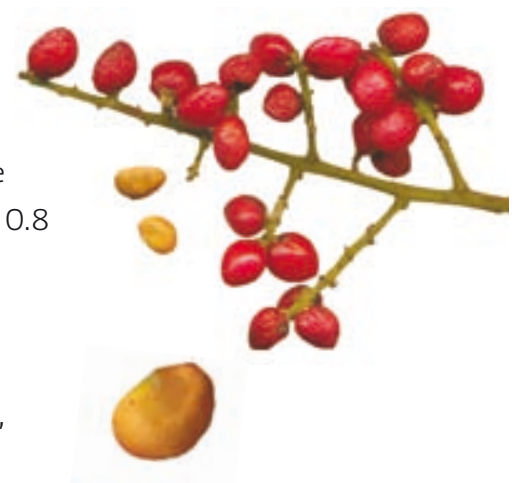




\section{Spondias radlkoferi J.D. Smith Anacardiaceae}

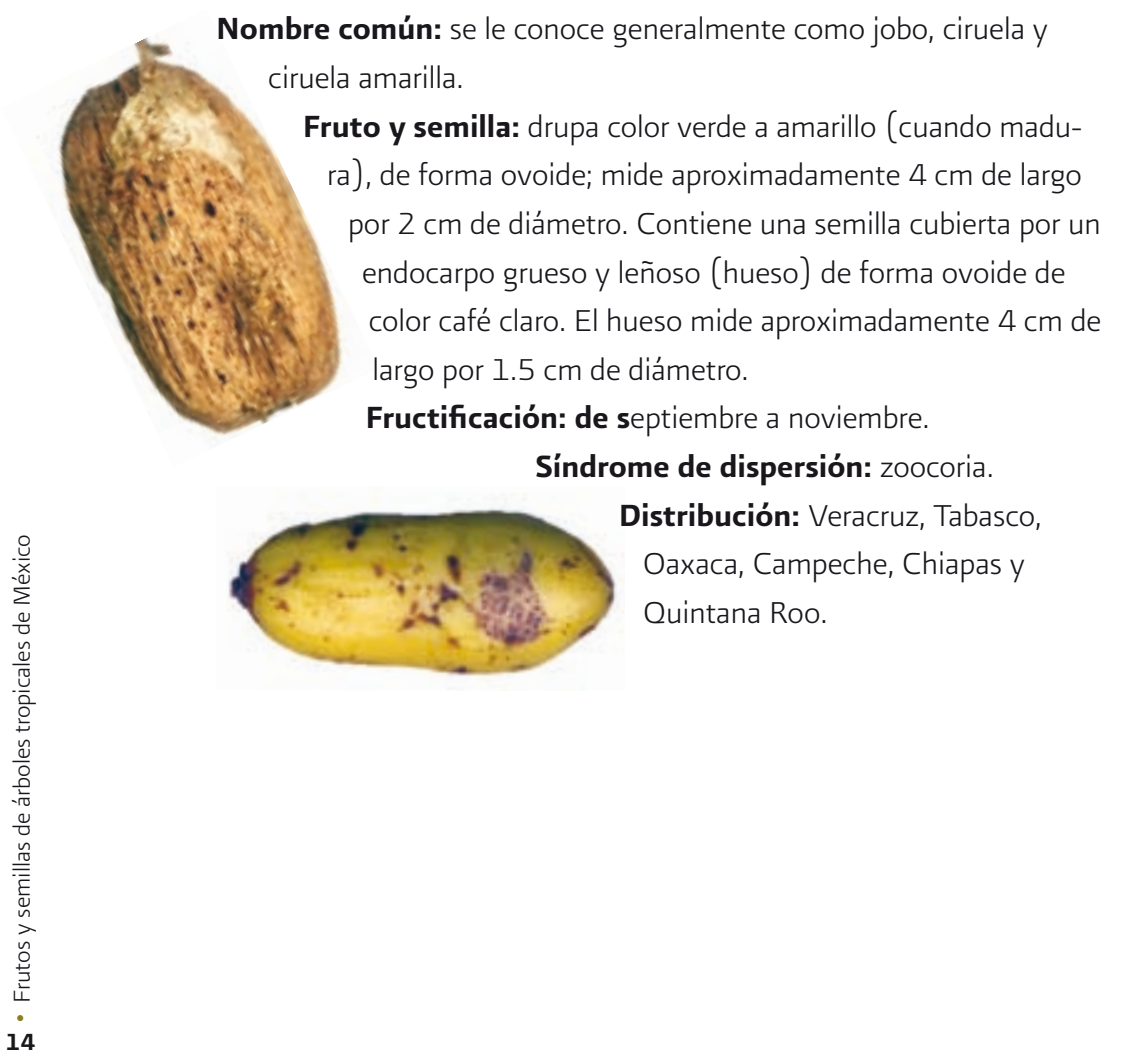




\section{Cymbopetalum baillonii R.E.Fr. Annonaceae}

Nombre común: en Veracruz: huevos de mono, flor de oreja. En Chiapas y Oaxaca: orejuela, orejuelo y guineíllo prieto.

Fruto y semilla: folículo alargado y curvo, parecido a un plátano. Mide aproximadamente de 6 a $9 \mathrm{~cm}$ de largo por 3 a $5 \mathrm{~cm}$ de ancho. Al madurar abre a la mitad. Las semillas son de color negro, un poco aplanadas, y están cubiertas por un arilo de color amarillo; miden hasta $2 \mathrm{~cm}$ de largo por 1 $\mathrm{cm}$ de ancho.

Fructificación: de mayo a noviembre. Síndrome de dispersión: zoocoria.

Distribución: Sierra Norte de Puebla, Veracruz, Tabasco, Chiapas, Guerrero y Oaxaca.
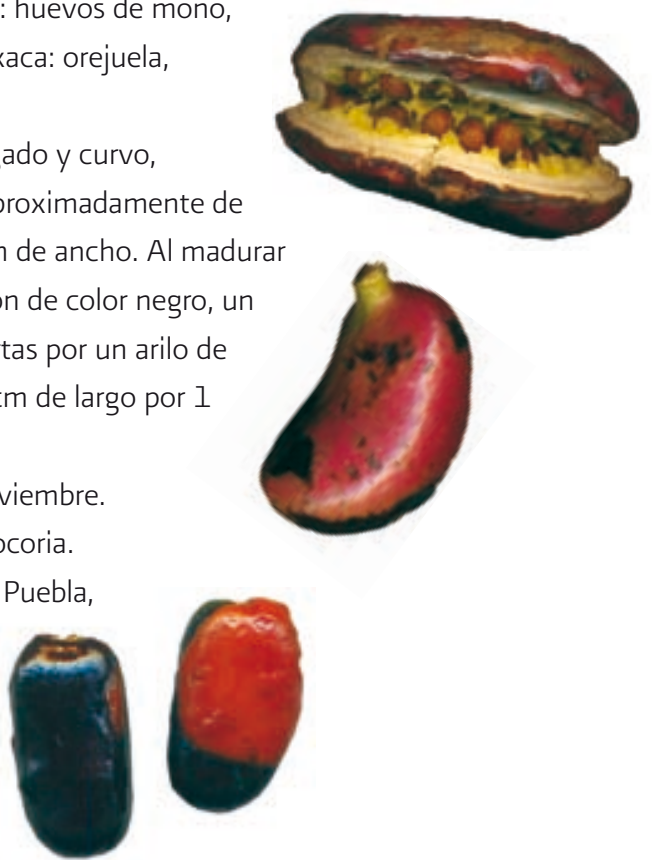


\section{Rollinia jimenezii Saff. Annonaceae}

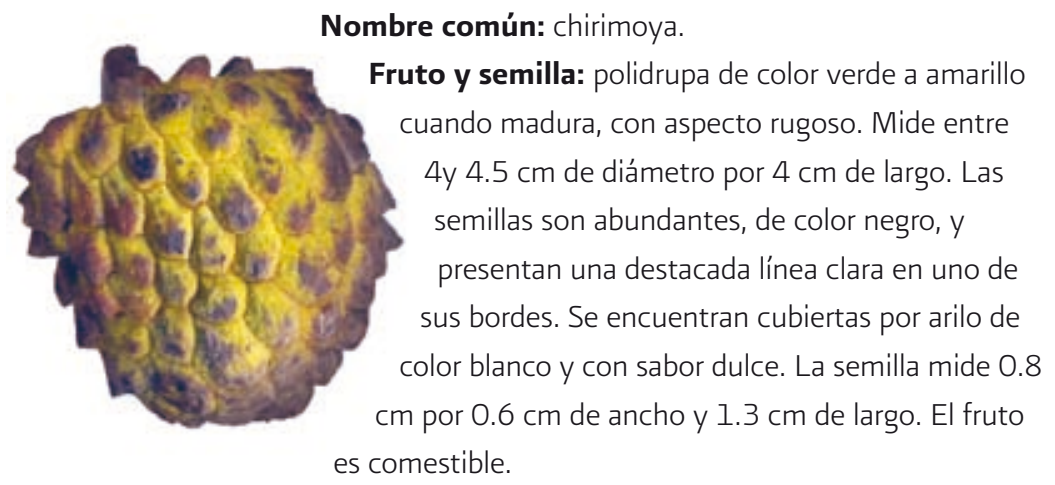

Fructificación: de agosto a noviembre. Síndrome de dispersión: zoocoria.

Distribución: Sierra Norte de Puebla, Veracruz, Tabasco y Chiapas. 


\section{Aspidosperma megalocarpo Muell.Arg. Apocynaceae}

Nombre común: en Veracruz: volador, nazareno. En Yucatán: pelmas. En Chiapas: ballester.

Fruto y semilla: folículo comprimido de color café oscuro y de forma oblonga. Mide aproximadamente $14 \mathrm{~cm}$ de largo y $12 \mathrm{~cm}$ de ancho. Contiene numerosas semillas aladas de color blanco a amarillo, que llegan am edir hasta $7 \mathrm{~cm}$ de diámetro, incluyendo el ala.

Fructificación: de mayo a junio. Síndrome de dispersión: anemocoria. Distribución: se encuentra en el Golfo de México, desde el centro de Veracruz hasta la península de Yucatán, y en el Pacífico desde Guerrero hasta Chiapas.
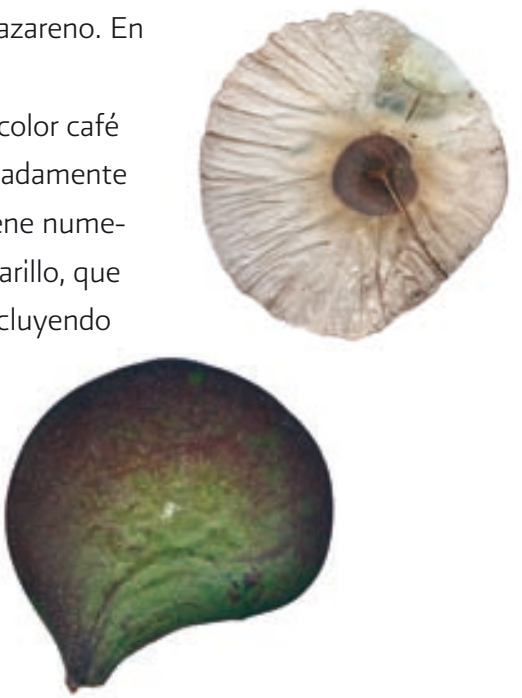


\section{Stemmadenia donnell-smithii (Rose) Woodson Apocynaceae}

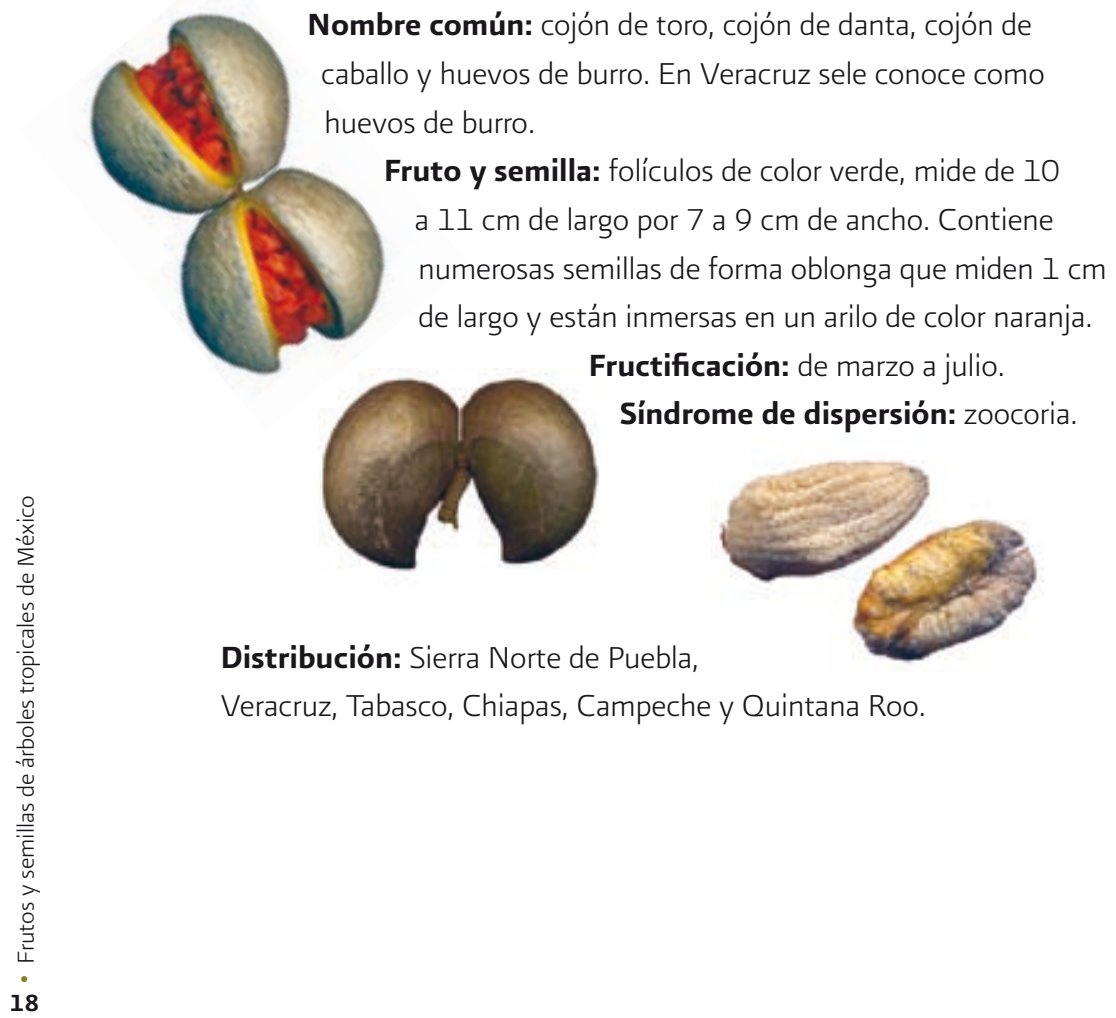




\section{Tabernaemontana alba Mill. Apocynaceae}

Nombre común: huevos de gato, cojón de gato, lecherillo, palo de San Diego.

Fruto y semilla: folículo de color verde claro; mide $7 \mathrm{~cm}$ de largo por $4.5 \mathrm{~cm}$ de ancho. Contiene numerosas semillas de forma oblonga alargadas de color café claro que miden $1 \mathrm{~cm}$ de largo por $0.3 \mathrm{~cm}$ de ancho. Las semillas están inmersas en arilo de color anaranjado. En uno de los costados de la semilla se observan líneas paralelas.

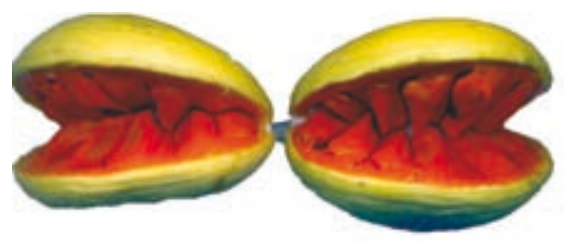

Fructificación: de mayo a octubre.

\section{Síndrome de dispersión:}

barocoria y zoocoria.

Distribución: Tamaulipas,

Querétaro, San Luis Potosí,

Puebla, Hidalgo, Veracruz,

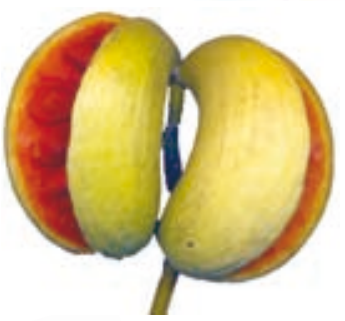

Oaxaca, Tabasco, Campeche,

Yucatán, Quintana Roo y Chiapas.

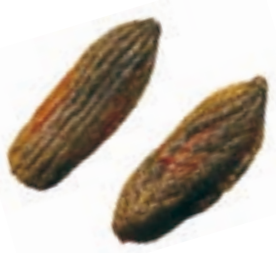




\title{
Dendropanax arboreus (L.) Decne. et Planch. Araliaceae
}

\author{
Nombre común: en Veracruz, palo de agua,
olivo. En Puebla, Oaxaca y Chiapas: mano de
danta y mano de león. En Oaxaca: palo blanco
y mano de sapo. En Durango y Sinaloa: mano
de oso. En Tamaulipas: palo santo. En San Luis
Potosí: palo santo y vidrioso. En Durango, pingüino.
}

Fruto y semilla: baya globosa ligeramente aplastada de color blanco a morado cuando madura, de $1 \mathrm{~cm}$ de diámetro por $0.9 \mathrm{~cm}$ de largo. Cada fruto puede tienen hasta siete semillas planas de color café claro que miden $0.4 \mathrm{~cm}$ de diámetro.

Fructificación: de septiembre a febrero.

Síndrome de dispersión: zoocoria.

Distribución: Sierra Norte de Puebla, sur de Tamaulipas y este de San Luis Potosí hasta la Península de Yucatán. En el Pacífico, desde Sinaloa hasta Chiapas. 


\section{Amphitecna tuxtlensis A.H.Gentry Bignoniaceae}

Nombre común: en Veracruz, jicarillo Fruto y semilla: cápsula cilíndrica de forma oblonga alargada; termina en ambos lados en punta de color verde. Mide hasta $17 \mathrm{~cm}$ de largo por 5.5 a $5.8 \mathrm{~cm}$ de ancho. Contiene numerosas semillas de color negro con forma de mariposa que miden hasta $2 \mathrm{~cm}$ de ancho por $1.2 \mathrm{~cm}$ de largo. Fructificación: todo el año.

\section{Síndrome de dispersión:}

barocoria.

Distribución: Veracruz, norte de Oaxaca y este de Tabasco.

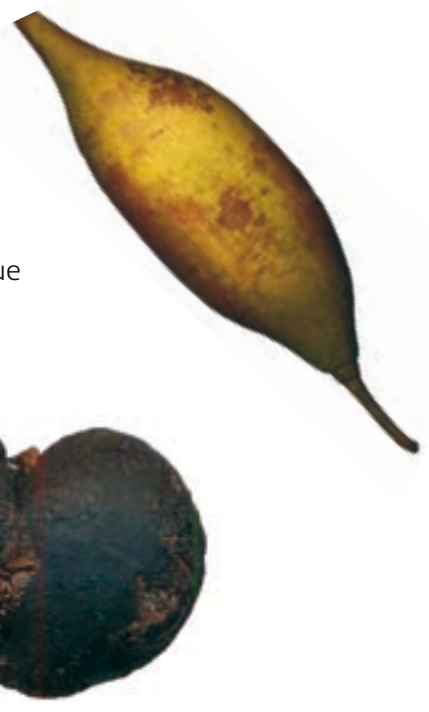




\section{Tabebuia rosea (Bertol.) DC. Bignoniaceae}

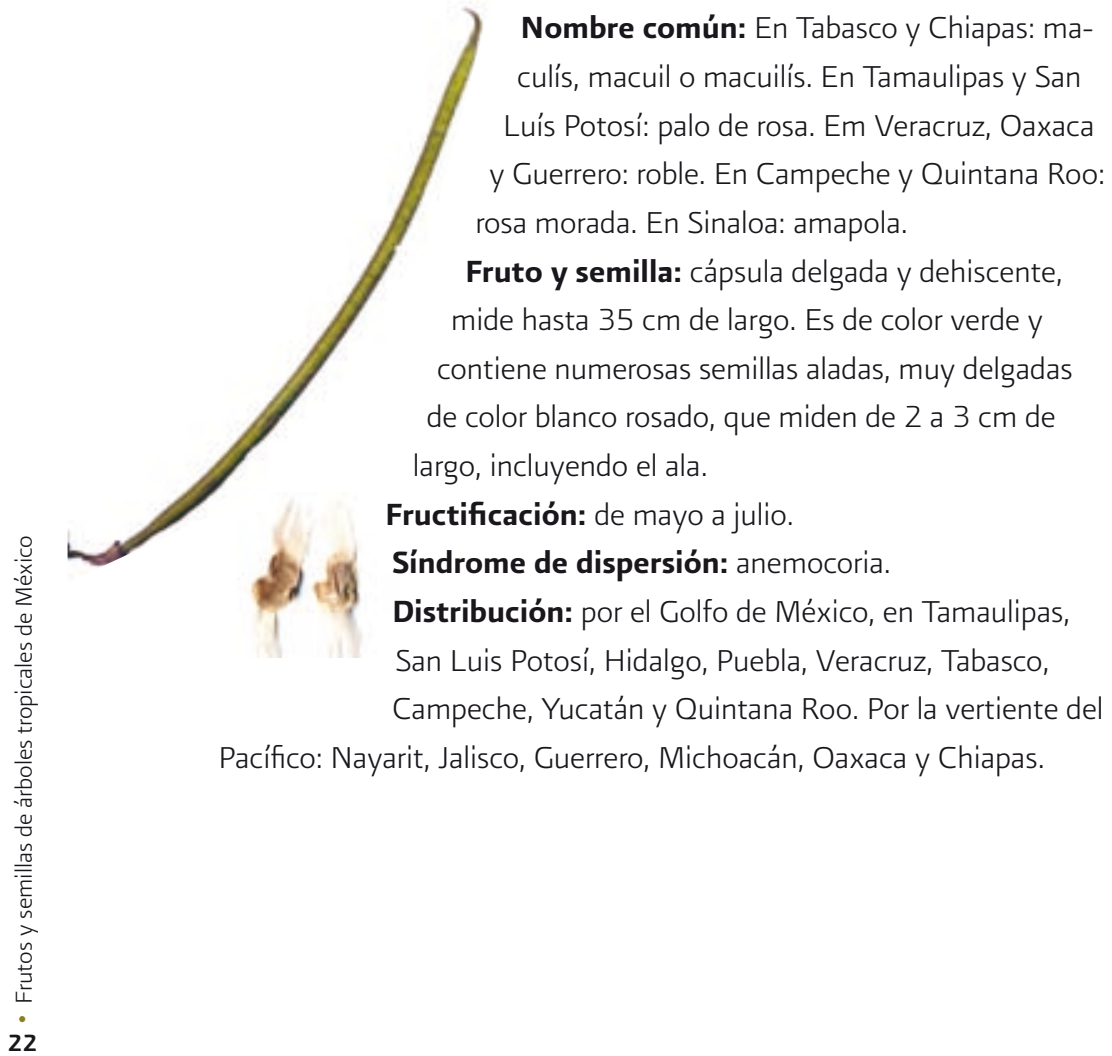




\section{Parmentiera aculeata (Kunth) Seem. Bignoniaceae}

Nombre común: cuajilote, cuachilote y guajilote. Fruto y semilla: baya alargada de aproximadamente $15 \mathrm{~cm}$ de largo por $5 \mathrm{~cm}$ de ancho. De color verde amarillento, presenta varios canales longitudinales. Contiene numerosas semillas pequeñas de $0.3 \mathrm{~cm}$ de diámetro de forma aplanada parecidas a las del chile. Fructificación: todo el año.

Síndrome de dispersión: zoocoria.

Distribución: se encuentra en todo el sureste del país y en los estados de Tamaulipas y San Luis Potosí.

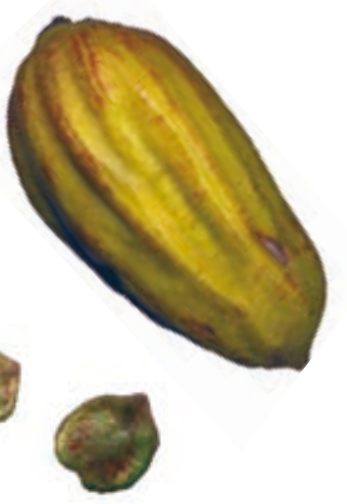




\section{Bernoullia flammea Oliver Bombacaceae}

Nombre común: en Veracruz: palo de tortilla, platanillo. En Oaxaca:

palo de calabaza. En Chiapas: palo de corcho, palo de cuesa, cosanté.

Fruto y semilla: cápsula que abre en 5 valvas, mide hasta $30 \mathrm{~cm}$ de largo, y es de color pardo. El fruto tiene numerosas semillas aladas de color amarillento, que miden (incluyendo el ala) de $5 \mathrm{~cm}$ a $7 \mathrm{~cm}$ de largo. La semilla sola mide entre $1 \mathrm{~cm}$ y $2 \mathrm{~cm}$ de diámetro.

Fructificación: de diciembre a abril.

Síndrome de dispersión: anemocoria.

Distribución: En el Golfo de México, se distribuye desde los Tuxtlas, en Veracruz hasta el norte de Chiapas. En la vertiente del Pacífico, desde Jalisco hasta Chiapas. 


\section{Ceiba pentandra (L.) Gaertner Bombacaceae}

Nombre común: pochote y ceiba.

Fruto y semilla: cápsula dehiscente que abre en 5 valvas, de forma ovada alargada de color verde. Mide entre $10 \mathrm{~cm}$ a $14 \mathrm{~cm}$ de largo y de 5 a $7 \mathrm{~cm}$ de diámetro. El fruto contiene numerosas semillas de forma ovoide de color café que miden entre 0.4 cm y $0.8 \mathrm{~cm}$ de largo. Las semillas están inmersas en una masa sedosa de color blanco.

Fructificación: de abril a junio.

Síndrome de dispersión: anemocoria. Distribución: en el Golfo de México, se extiende desde Tamaulipas hasta la península de Yucatán e Isla de Cozumel; y por el Pacífico, desde el Sur de Sonora hasta Chiapas.
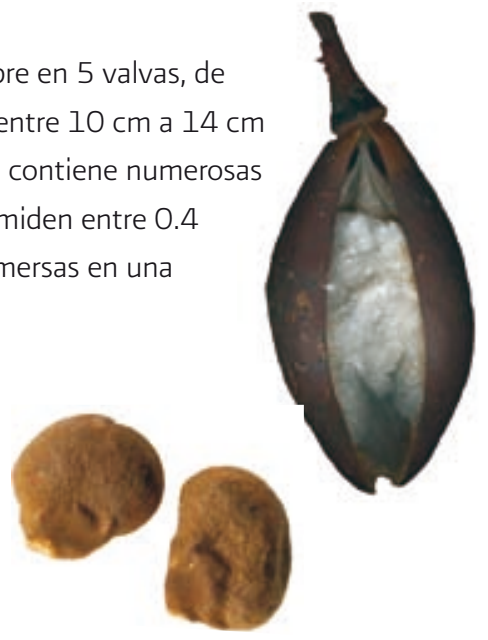


\section{Ochroma pyramidale (Cav. ex Ham.) Urb. Bombacaceae}

Nombre común: En Chiapas y Tabasco; jonote real, balsa, jopi y corcho. En Oaxaca: pepe balsa. En Veracruz: pochote y cola de gato. Fruto y semilla: cápsula dehiscente que abre en 5 valvas. Mide de $10 \mathrm{~cm}$ a $20 \mathrm{~cm}$ de largo por $2.5 \mathrm{~cm}$ de ancho. Se observan en el fruto inmaduro 10 costillas prominentes. Al madurar se cubre de numerosos vellos sedosos de color café claro. Las semillas son de forma ovoide y color café oscuro de aproximadamente $0.5 \mathrm{~cm}$ de largo. Las semillas se encuentran inmersas en filamentos fibrosos dentro del fruto, que al abrise permite que las semillas dentro de los filamentos floten y las disperse el viento.

Fructificación: de ebrero a julio.

Síndrome de dispersión: anemocoria.

Distribución: noreste de Oaxaca, Chiapas, Tabasco y sur de Veracruz. 


\section{Pachira aquatica Aubl. Bombacaceae}

Nombre común: palo de agua, apompo, zapote de agua y palo bobo.

Fruto y semilla: cápsula dehiscente de color café y de forma oblonga alargada. Mide hasta $25 \mathrm{~cm}$ de largo. Abre en 5 valvas y contiene numerosas semillas con forma de campana de aproximadamente $5 \mathrm{~cm}$ de diámetro.

Fructificación: todo el año.

Síndrome de dispersión: hidrocoria y barocoria.

Distribución: Puebla, Veracruz, Tabasco, Campeche, Yucatán, Chiapas, Quintana Roo y Guerrero.
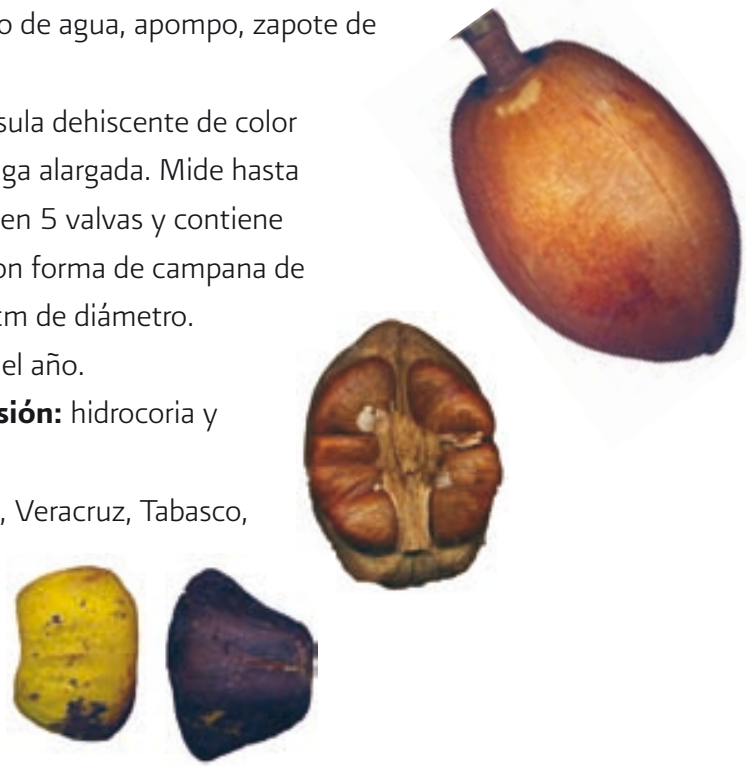


\section{Cordia alliodora (Ruiz et Pavón) Oken Boraginaceae}
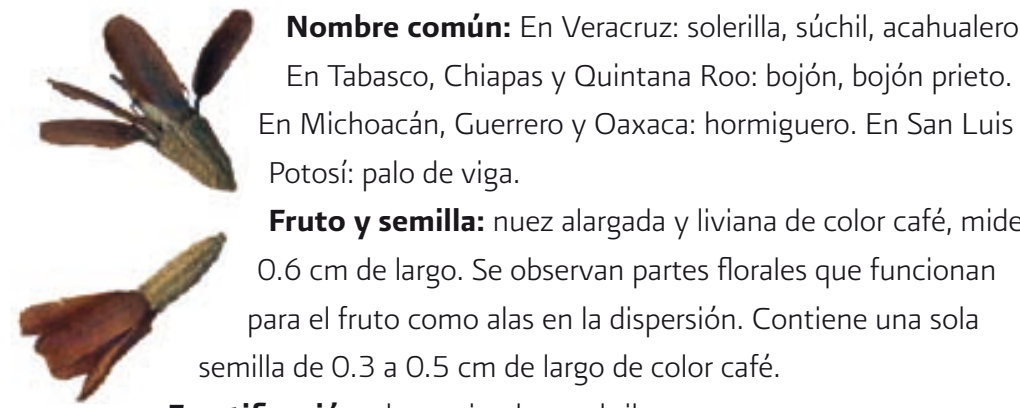

Fruto y semilla: nuez alargada y liviana de color café, mide $0.6 \mathrm{~cm}$ de largo. Se observan partes florales que funcionan para el fruto como alas en la dispersión. Contiene una sola semilla de 0.3 a $0.5 \mathrm{~cm}$ de largo de color café.

Fructificación: de septiembre a abril.

Síndrome de dispersión: anemocoria.

Distribución: Tamaulipas, San Luis Potosí, Veracruz, Tabasco, Quintana Roo, Campeche y Yucatán. En el Pacífico, desde Sinaloa hasta Chiapas. 


\section{Cordia diversifolia Pavón ex A.DC. Boraginaceae}

Nombre común: En Chiapas: bojón blanco.

Fruto y semilla: drupa de forma ovoide de color verde que se torna blanca cuando madura. Mide $0.8 \mathrm{~cm}$ de diámetro por $1.3 \mathrm{~cm}$ de alto. Tiene una semilla con testa dura, áspera al tacto y de forma irregular, con prolongaciones en forma de picos, mide aproximadamente $0.5 \mathrm{~cm}$ de largo por $0.8 \mathrm{~cm}$ de diámetro.

Fructificación: de julio a septiembre.

Síndrome de dispersión: barocoria.

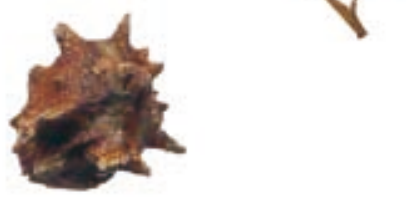

Distribución: Nayarit, Veracruz, Tabasco,

Campeche, Chiapas, Jalisco, Guerrero y Oaxaca. 


\section{Cordia megalantha Blake Boraginaceae}

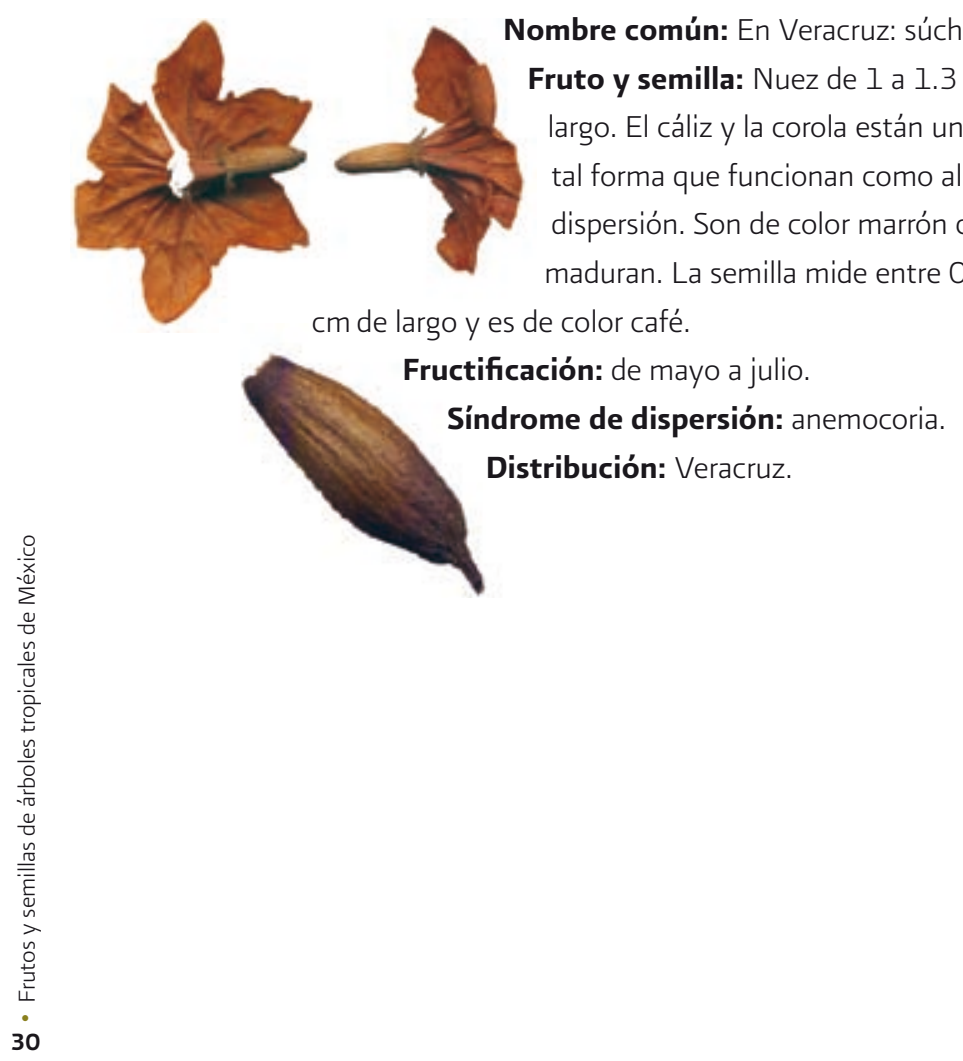




\section{Rochefortia lundellii Camp Boraginaceae}

Nombre común: palo dulce.

Fruto y semilla: drupa de forma globosa de color amarillo a negro pasando por el rojo cuando madura. Mide $1 \mathrm{~cm}$ de diámetro, contiene cuatro semillas en forma de gajo, miden de $0.3 \mathrm{~cm}$ a $0.4 \mathrm{~cm}$ de ancho por $0.5 \mathrm{~cm}$ de largo. En la semilla se observan líneas longitudinales truncas que asemejan arrugas.

Fructificación: de septiembre a dDiciembre.

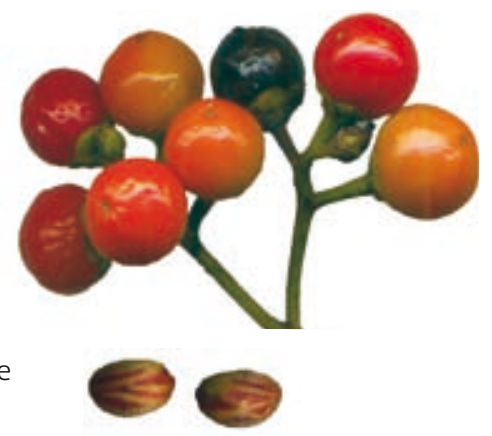
Síndrome de dispersión: zoocoria.

Distribución: Veracruz, Chiapas, Quintana Roo y Campeche. 


\section{Bursera simaruba (L.) Sarg. Burseraceae}

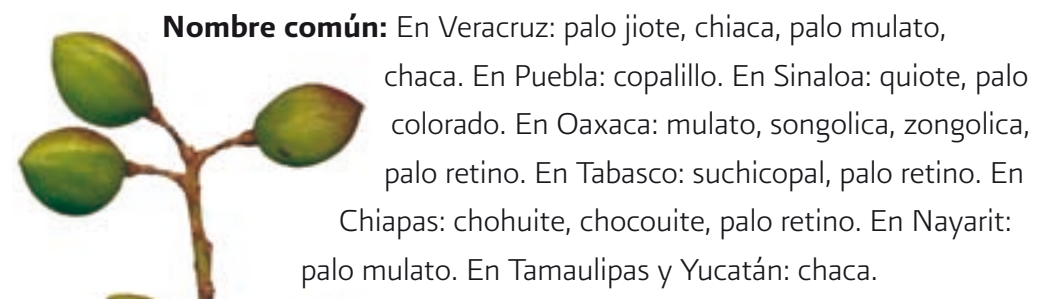

Frutos y semillas: cápsula trivalvada de color verde a rojizo cuando madura y de forma globosa. Mide $1.0 \mathrm{~cm}$ de largo y 0.15 de diámetro. Contiene una o dos semillas de aproximadamente $0.10 \mathrm{~cm}$ de largo por 0.7 a $0.8 \mathrm{~cm}$ ancho y 0.5 a $0.65 \mathrm{~cm}$ de grueso, de color amarillo cubiertas por arilo de color rojo.

Fructificación: de o ctubre a marzo.

Síndrome de dispersión: zoocoria y barocoria.

Distribución: Tamaulipas, San Luis Potosí, Veracruz, Chiapas, Tabasco, Quintana Roo, Campeche, Yucatán, y en el Pacifico desde Sinaloa hasta Chiapas. 


\section{Protium copal (Schltdl. \& Cham.) Engl. Burseraceae}

Nombre común: se le conoce generalmente como copal. Fruto y semilla: cápsula dehiscente de forma esférica que abre en 3 o 4 valvas. Los frutos son de color rojo al madurar, de $2.3 \mathrm{~cm}$ a $2.5 \mathrm{~cm}$ de diámetro. Contiene de una a cuatro semillas negras de forma oblonga alargada, aplanadas por un lado y curvas por el otro. Están envueltas en un arilo color blanco, y miden de $1 \mathrm{~cm}$ a $1.5 \mathrm{~cm}$ de ancho por $1.6 \mathrm{~cm}$ de largo.

Fructificación: de marzo a agosto.

Síndrome de dispersión: zoocoria.

Distribución: San Luis Potosí, Tamaulipas,

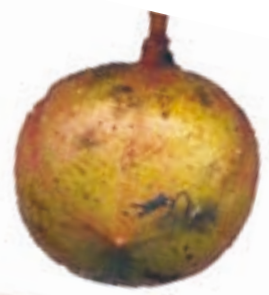
Veracruz, Tabasco, Campeche, Quintana Roo, Sur este de Oaxaca y Chiapas. 


\section{Carica papaya $\mathrm{L}$. Caricaceae}

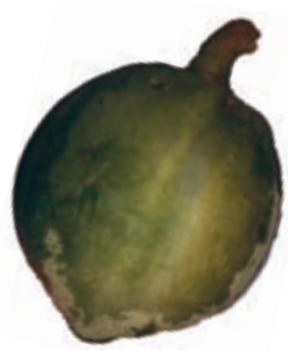

Nombre común: papaya.

Fruto y semilla: baya de forma globosa de color verde a amarillo cuando madura, que mide 6 a $7 \mathrm{~cm}$ de largo por $4.5 \mathrm{~cm}$ de diámetro. Contiene numerosas semillas rugosas de color negro de forma esférica, de $0.5 \mathrm{~cm}$ de largo por $0.3 \mathrm{~cm}$ de ancho. Presentan un funículo de color claro el cual las sujeta al fruto. El fruto es comestible.

Fructificación: todo el año.

Síndrome de dispersión: zoocoria.

Distribución: en el Pacífico, desde Nayarit hasta Chiapas y por el Golfo de México, Veracruz, Tabasco, Isla Cozumel, Quintana Roo,

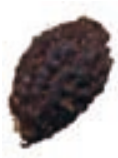
Campeche y Chiapas. 


\section{Capparis mollicella Standl. Capparidaceae}

Fruto y semilla: baya carnosa alargada, de color verde a café cuando madura. Se observa en el fruto una línea longitudinal que atraviesa por la mitad al fruto. Mide $5 \mathrm{~cm}$ de ancho por $17 \mathrm{~cm}$ de largo. Contiene hasta 18 semillas de color café, inmersas en un arilo color blanco, con olor dulce, de $0.8 \mathrm{~cm}$ de ancho por $1.2 \mathrm{~cm}$ de largo. La semilla tiene en uno de sus lados una pequeña protuberancia.

Fructificación: de enero a julio.

Síndrome de dispersión: barocoria Distribución: Sierra de Manantlán (Jalisco y Colima), Sierra Norte de Puebla, Veracruz, Tabasco, Oaxaca y Chiapas.
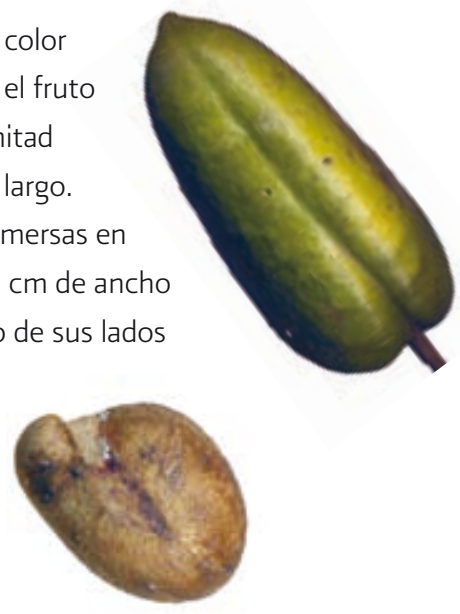


\section{Cecropia obtusifolia Bertol. Cecropiaceae}

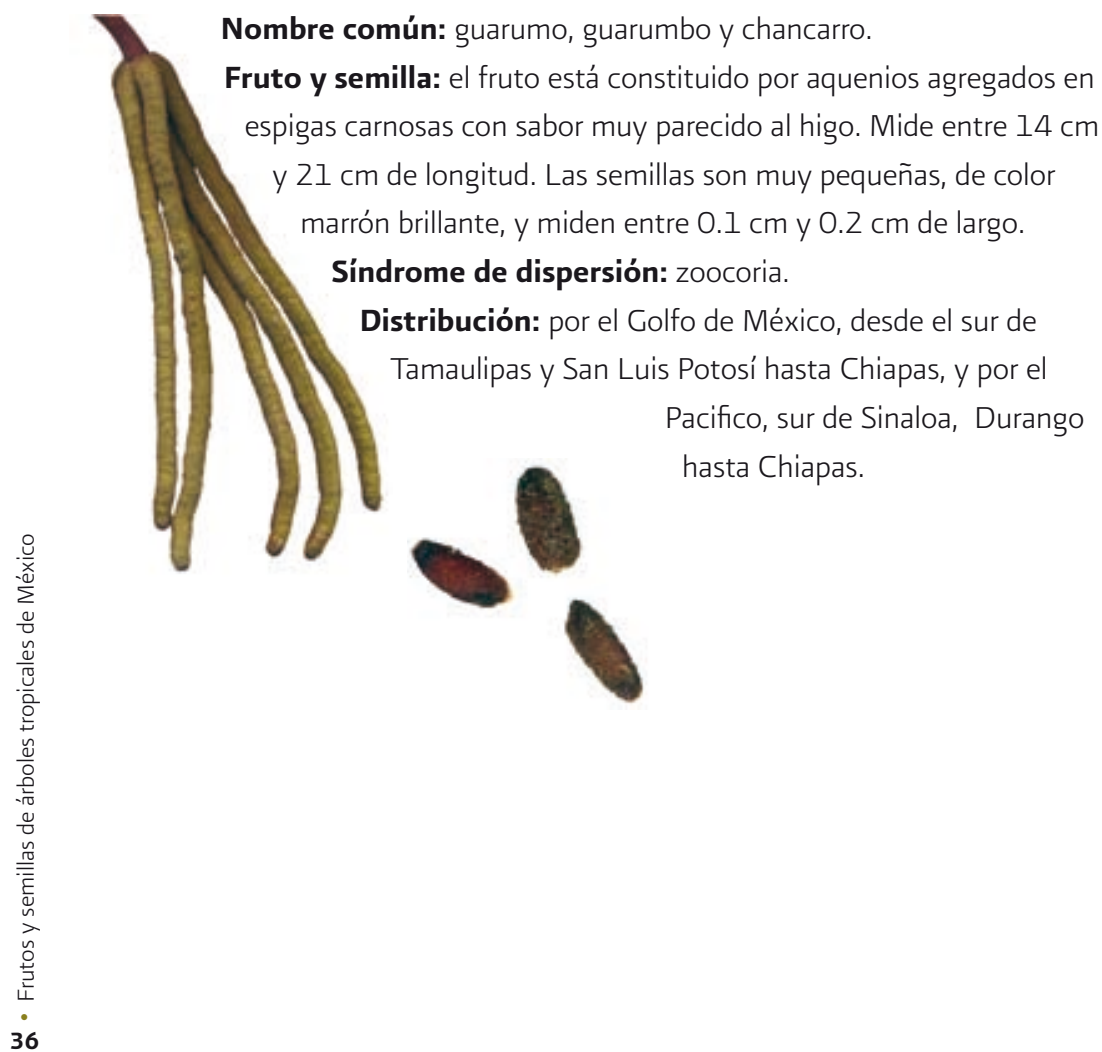




\section{Hirtella triandra Sw. Chrysobalanaceae}

Nombre común: en Veracruz: palo blanco. En Chiapas: aceituno

Fruto y semilla: drupa morada de forma obovada aplanada, mide $1 \mathrm{~cm}$ de ancho por $1.5 \mathrm{~cm}$ de largo. Contiene una sola semilla de forma obovada aplanada de color café, de $0.7 \mathrm{~cm}$ de ancho por $1 \mathrm{~cm}$ de largo.

Fructificación: de mayo a julio.

\section{Síndrome de dispersión:}

zoocoria.

Distribución: Sierra Norte de Puebla, Veracruz, Tabasco y Chiapas.
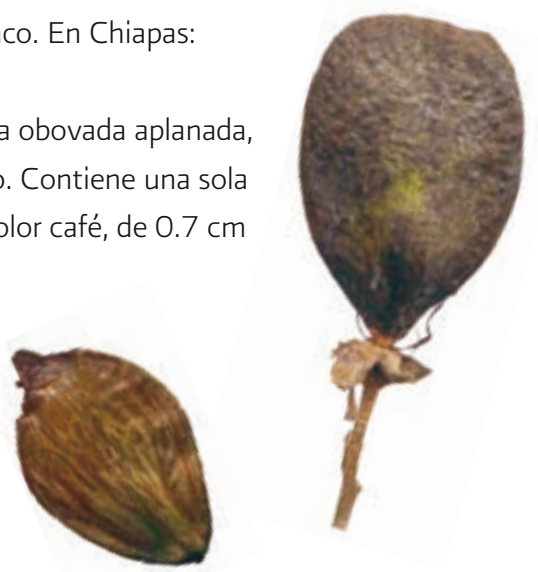


\section{Licania platypus (Hemsl.) Fritsch Chrysobalanaceae}

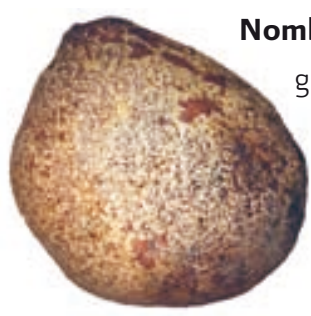

Nombre común: en Veracruz: zapote de mico. En Oaxaca: guelau. En Chiapas: pio, sonzapote, cabeza de mico. En Guerrero y Michoacán: huicume.

Fruto y semilla: drupa carnoza de forma globosa, de color café con la cubierta aspera y dura, que mide hasta $14 \mathrm{~cm}$ de largo y $11 \mathrm{~cm}$ de diámetro. El fruto contiene una sola semilla rodeada por un endospermo

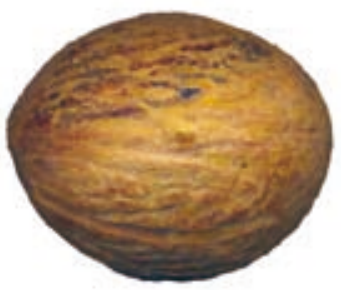
duro (hueso) de forma globosa, que puede alcanzar hasta $9 \mathrm{~cm}$ de diámetro. El hueso está cubierto por un mesocarpo fibroso de color amarillo y de olor dulce.

Fructificación: de julio a mayo.

Sindrome de dispersión: barocoria.

Distribucion: Veracruz, Puebla, Tabasco y Chiapas, y por la vertiente del Pacífico, desde Jalisco hasta Chiapas. 


\section{Cochlospermum vitifolium (Willd.) Spreng. Cochlospermaceae}

Nombre común: En Oaxaca, Veacruz y Puebla: pongolote. En Oaxaca: cojón de toro, coquito. En Tabasco: guate. En Veracruz: mirasol. En Durango: palo amarillo. En Michoacán: panigua y en Guerrero, panaco.

Fruto y semilla: cápsula dehiscente verde y de forma globosa que al madurar es de color café. Mide entre $7 \mathrm{~cm}$ y $9 \mathrm{~cm}$ de largo, se abre en 5 valvas. El fruto contiene numerosas semillas en forma de e de color negro, de aproximadamente $0.5 \mathrm{~cm}$ de diámetro, y están rodeadas por una abundante masa sedosa de color claro.

Fructificación: $d \epsilon$ enero a junio. Síndrome de dispersión: anemocoria.

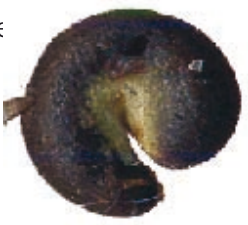




\section{Terminalia amazonia Exell (Gmelin) Exell Combretaceae}

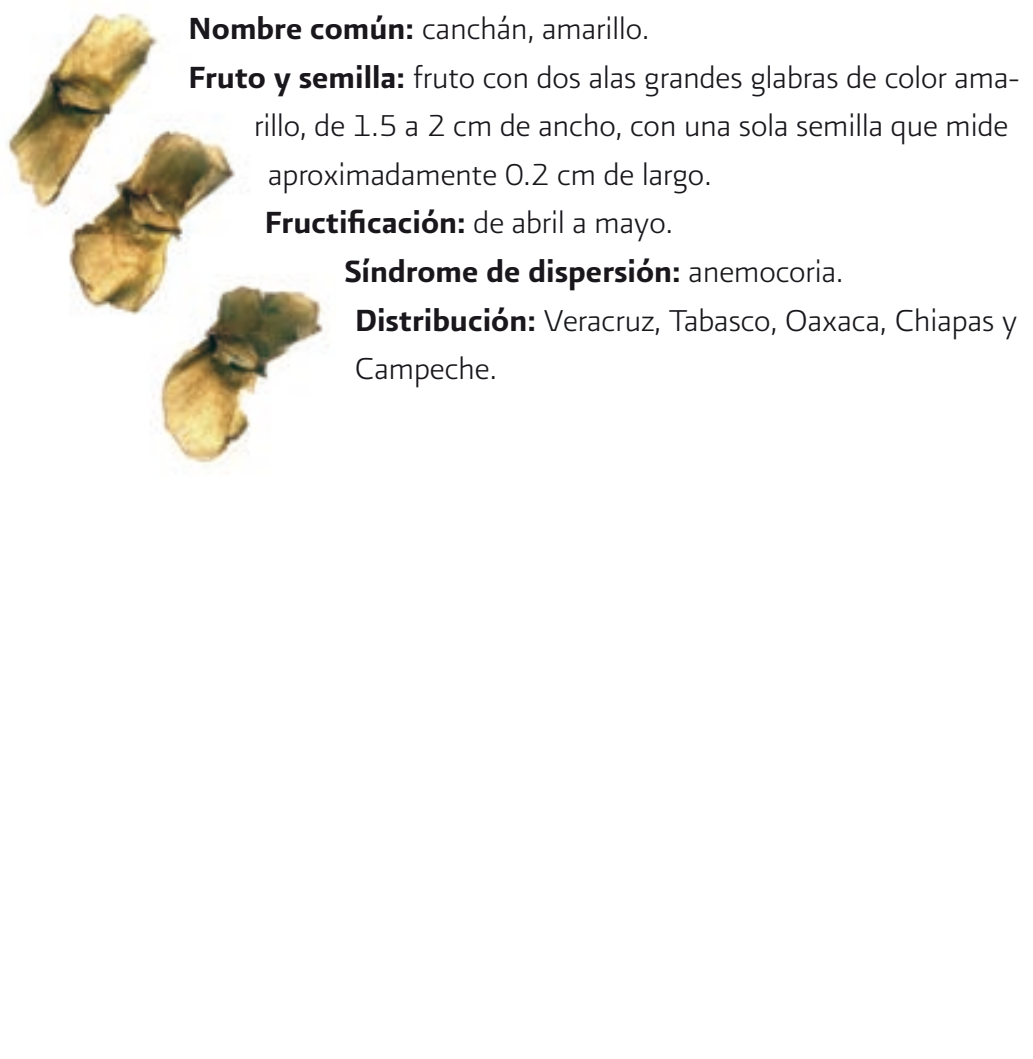




\section{Diospyros digyna Jacq. Ebenaceae}

Nombre común: zapote negro o zapote prieto. Fruto y semilla: baya comestible globosa de $7 \mathrm{~cm}$ de diámetro de color verde. Contiene hasta 10 semillas de $3 \mathrm{~cm}$ de largo, de color café oscuro, inmersas en un arilo negro y de sabor dulce cuando madura.

Fructificación: de agosto a enero.

Síndrome de dispersión: zoocoria.

Distribución: norte de Puebla, Veracruz, Chiapas, Yucatán, y en las costas de Jalisco, Guerrero, Michoacán y Oaxaca.
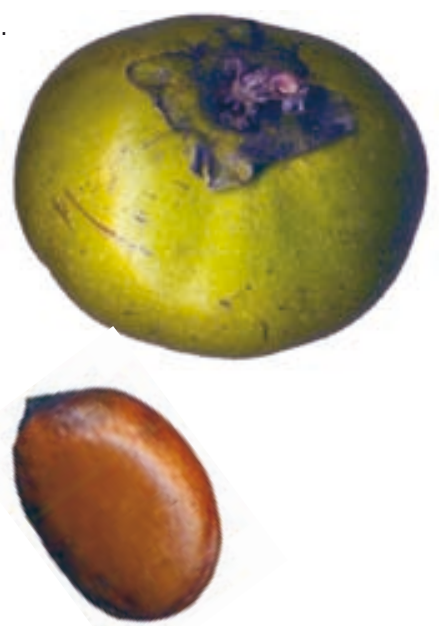


\section{Muntingia calabura L. Elaeocarpaceae}

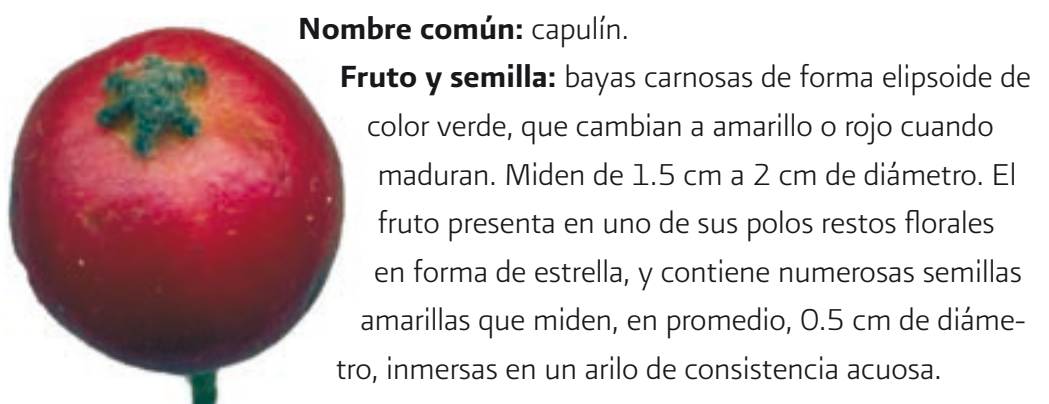

Fructificación: de abril a agosto.

Síndrome de dispersión: zoocoria.

Distribución: en la vertiente del Pacífico, desde Nayarit hasta Chiapas, y en la vertiente del Golfo de México, desde Tamaulipas hasta la península de Yucatán. 


\section{Erythroxylum tabascense Britton Erythroxylaceae}

Nombre común: agusa, escobillo.

Fruto y semilla: drupa roja de $0.6 \mathrm{~cm}$ de ancho por $1.5 \mathrm{~cm}$ de largo y de forma oblonga alargada; tiene una semilla de la misma forma que el fruto que mide $0.5 \mathrm{~cm}$ de ancho por $1.4 \mathrm{~cm}$ de largo, y es de color café claro. Presenta canales que recorren longitudinalmente la semilla.

Fructificación: de junio a agosto.

Síndrome de dispersión: zoocoria.

Distribución: Veracruz, Tabasco y Chiapas.
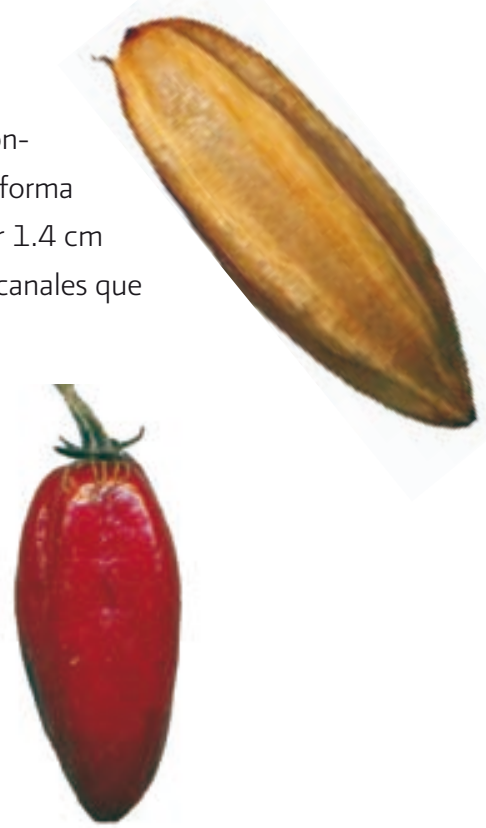


\section{Adelia barbinervis Schltr. \& Cham. Euphorbiaceae}

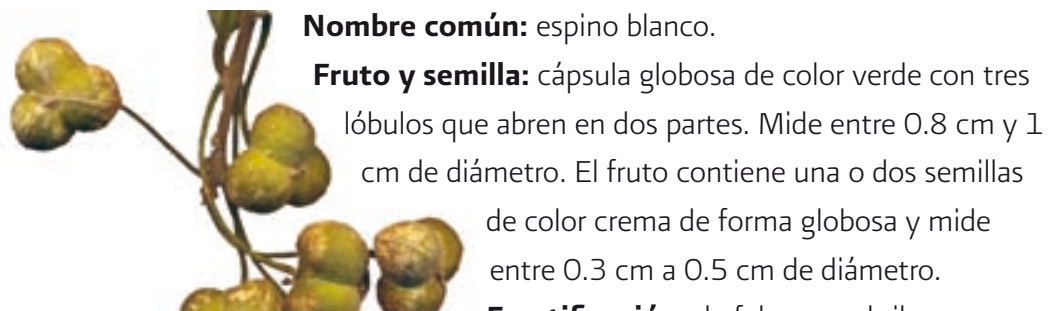

Fructificación: de febrero a abril.

Síndrome de dispersión: barocoria

Distribución: Querétaro (Sierra Gorda),

Puebla, Hidalgo, San Luis Potosí, Tamaulipas,

Veracruz, Tabasco, Isla Cozumel, Quintana Roo, Yucatán, Chiapas, Oaxaca (Los Chimalapas), Sinaloa y Jalisco. 


\section{Croton schiedeanus Schldl. Euphorbiaceae}

Nombre común: cascarillo.

Fruto y semilla: cápsula trilobulada, dehiscente de color grisáceo que abre en seis valvas. Mide 1.0 $\mathrm{cm}$ de diámetro. La cubierta del fruto es granulosa. El fruto contiene tres semillas en forma de gajo, de $0.8 \mathrm{~cm}$ de largo, de color café con manchas claras. Fructificación: de abril a mayo.

\section{Síndrome de dispersión:}

barocoria.

Distribución: Nayarit, Campeche, Veracruz, Tabasco y Chiapas.

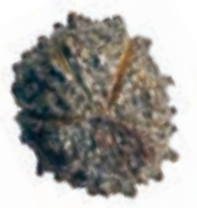




\section{Omphalea oleifera Hemsl. Euphorbiaceae}

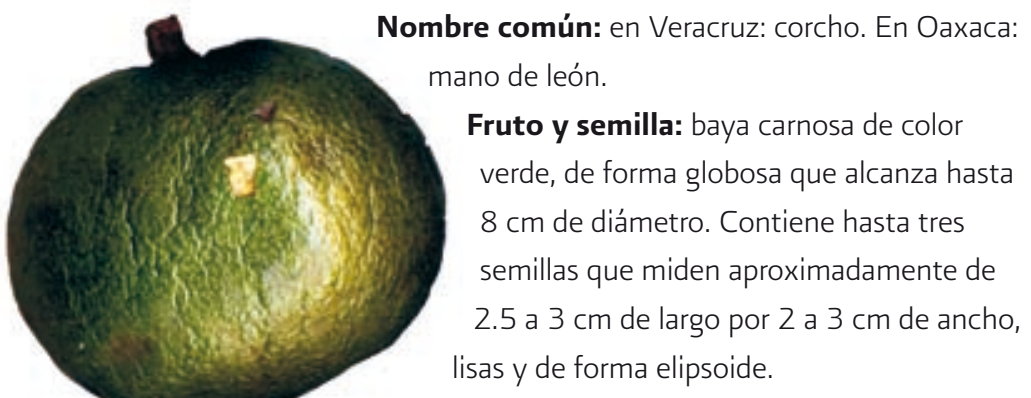

Fructificación: de marzo a octubre.

Síndrome de dispersión: barocoria.

Distribución: Veracruz (Los Tuxtlas), noreste de Oaxaca, Sur de Chiapas y en la frontera entre Chiapas y Tabasco. 


\section{Pleuranthodendron lindenii (Turcz.) Sleumer Flacourtiaceae}

Nombre común: en Oaxaca: golondrina, pochitaquillo. En Veracruz y Chiapas: catarrita. En San Luís Potosí: maicillo.

Fruto y semilla: baya globosa de color crema que mide aproximadamente $0.8 \mathrm{~cm}$ de diámetro. Contiene una sola semilla de color verde oscuro de 0.4 a $0.6 \mathrm{~cm}$ de diámetro. Tiene un olor semejante al cacahuate. La semilla tiene una línea larga y delgada en uno de sus costados.

Fructificación: de agosto a noviembre.

Síndrome de dispersión: barocoria.

Distribución: Sierra Norte de Puebla, Puebla, San Luis Potosí, Veracruz, Chiapas y Oaxaca. 


\section{Zuelania guidonia (Sw.) Britt. \& Millsp. Flacourtiaceae}

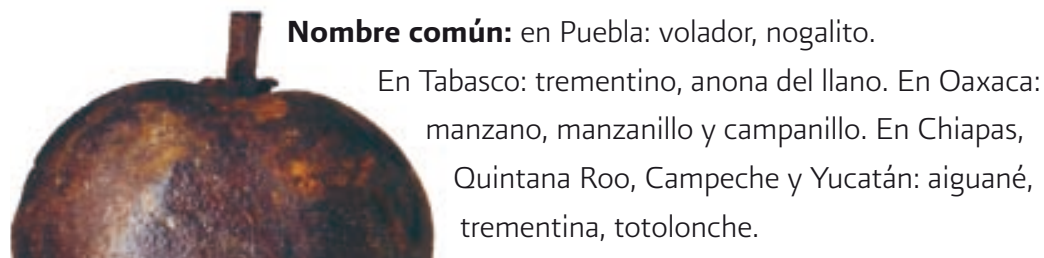

Fruto y semilla: cápsula dehiscente, de forma globosa de $8.0 \mathrm{~cm}$ de diámetro, de color oscuro y de consistencia dura cuando madura.

El fruto contiene numerosas semillas de forma nhlnnoa v de color café, que miden aproximadamenlargo por $0.3 \mathrm{~cm}$ de ancho.

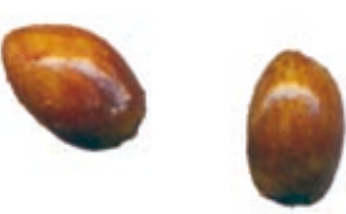
Fructificación: de bril a julio.

Síndrome de dispersión: barocoria.

Distribución: sur de Tamaulipas, sude San Luis Potosí, Veracruz, Tabasco, Campeche, la Península de Yucatán, sur este de Oaxaca y Chiapas. 


\section{Calophyllum brasiliense Cambess. Guttiferae}

Nombre común: en Veracruz: ocú. En Tabasco, Chiapas y Oaxaca: baríl, barí, leche María, leche amarilla. En Oaxaca: cedro cimarrón. En Chiapas y Tabasco: guaya.

Semillas y frutos: drupa globosa que mide $3 \mathrm{~cm}$ de diámetro de color crema. El fruto contiene una semilla de forma globosa de color café oscuro cuando madura. Mide de 1 a cm a 1.3 cm de diámetro. El hueso es café claro, mide de $1.4 \mathrm{~cm}$ a $1.6 \mathrm{~cm}$ de diámetro. Fructificación: de septiembre a noviembre.

Síndrome de dispersión: barocoria.

Distribución: Veracruz, Tabasco, Chiapas, Quintana Roo,
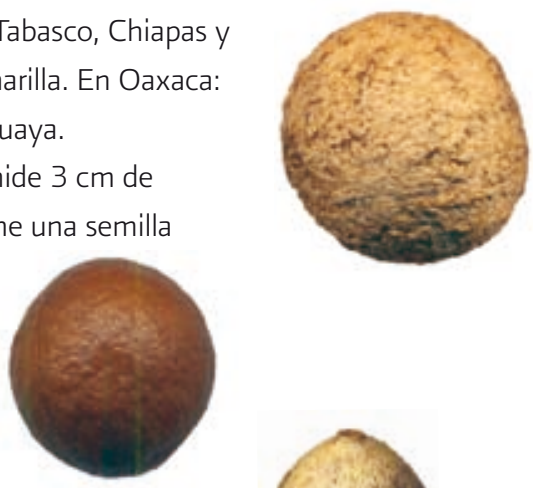
Yucatán y en el Pacífico desde Nayarit hasta Chiapas.

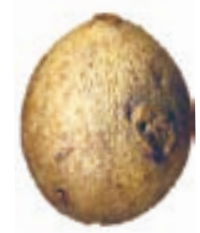




\section{Rheedia edulis Triana \& Planch. Guttiferae}

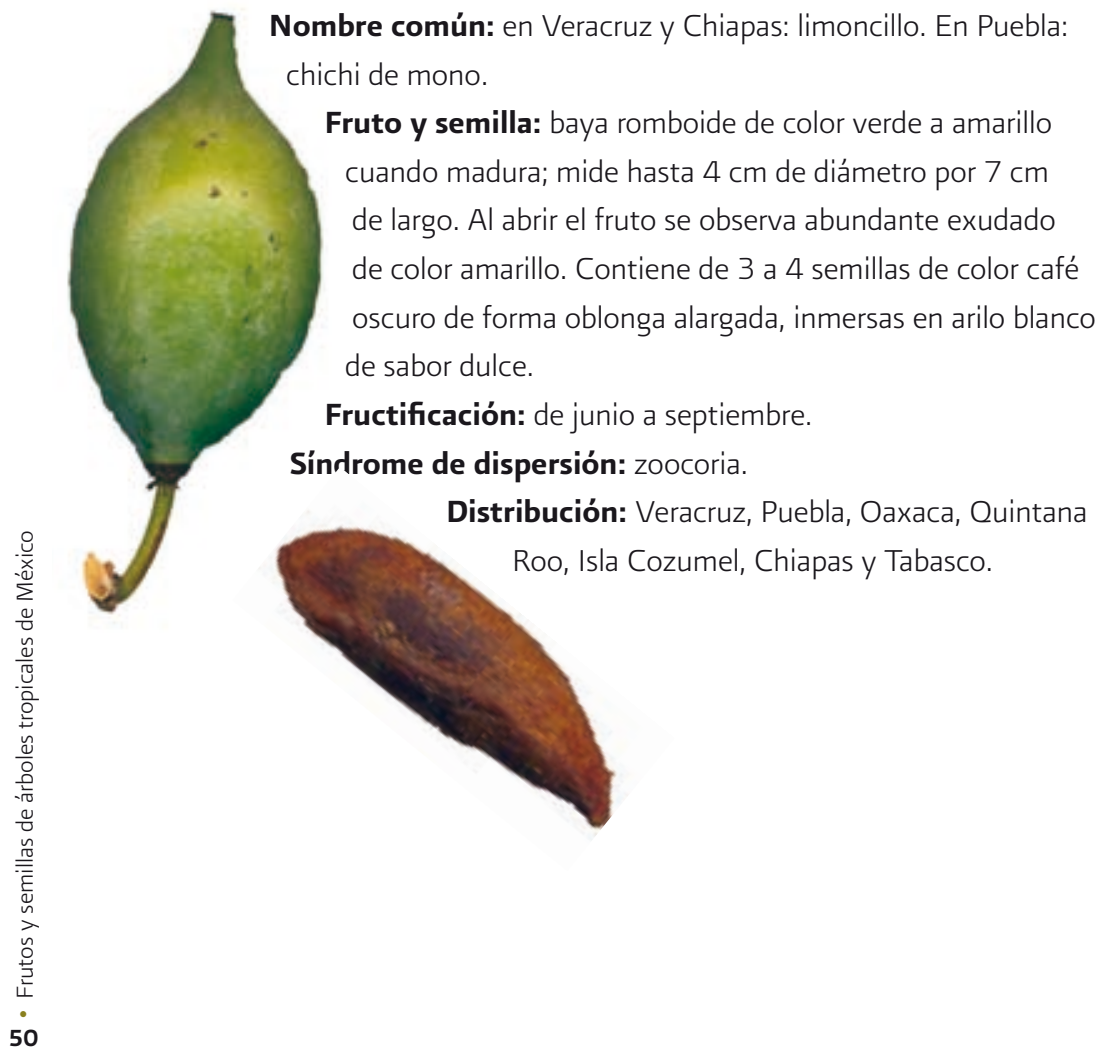




\section{Calatola laevigata Standl. Icacinaceae}

Nombre común: en Veracruz: nuez. En Oaxaca y Chiapas: duraznillo.

Fruto y semilla: drupa de forma esférica. Mide aproximadamente $7 \mathrm{~cm}$ de largo por $5 \mathrm{~cm}$ de ancho, de color verde a negro cuando madura. El hueso es de color café claro, con prominentes crestas longitudinales. La semilla es ovoide de 5 $\mathrm{cm}$ de largo por $4 \mathrm{~cm}$ de ancho y de color café claro.

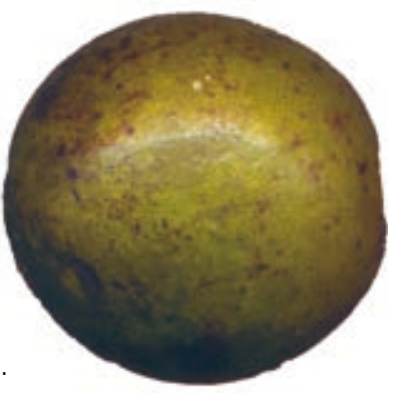
Fructificación: de noviembre a marzo. Síndrome de dispersión: barocoria. Distribución: Sierra Norte de Puebla, Veracruz, Oaxaca y Chiapas.

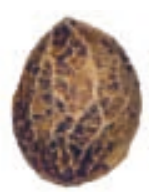




\section{Nectandra ambigens (Blake) Allen Lauraceae}

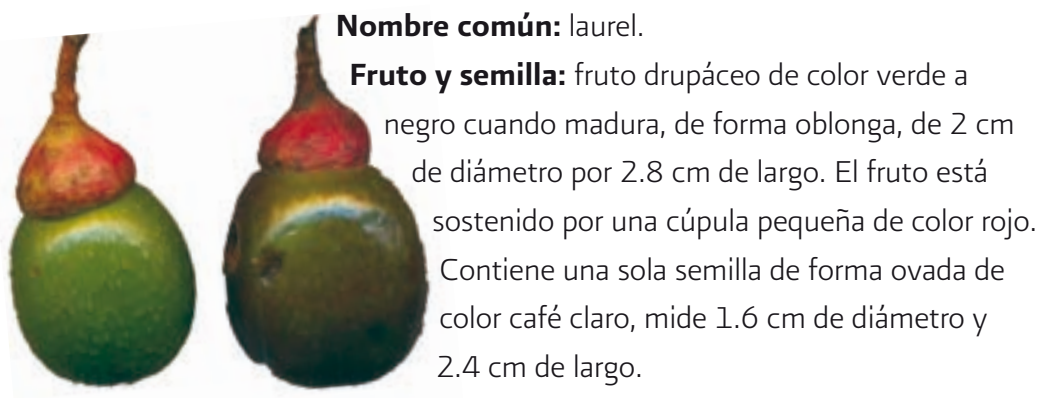

Fructificación: de agosto a noviembre.

Síndrome de dispersión: barocoria y zoocoria.

Distribución: sur de Veracruz y sureste de Chiapas, Guerrero, Oaxaca. 


\section{Nectandra reticulata (Ruiz et Pavón) Mez Lauraceae}

Nombre común: contra.

Fruto y semilla: fruto drupáceo de forma globosa de color verde a negro cuando maduran, que mide 1 $\mathrm{cm}$ de diámetro. El fruto está sostenido por una cúpula muy pequeña de color rojo, y tiene una semilla esférica de color café de $0.7 \mathrm{~cm}$ de diámetro.

Fructificación: de septiembre a octubre. Síndrome de dispersión: barocoria y zoocoria.

Distribución: Veracruz y Chiapas.

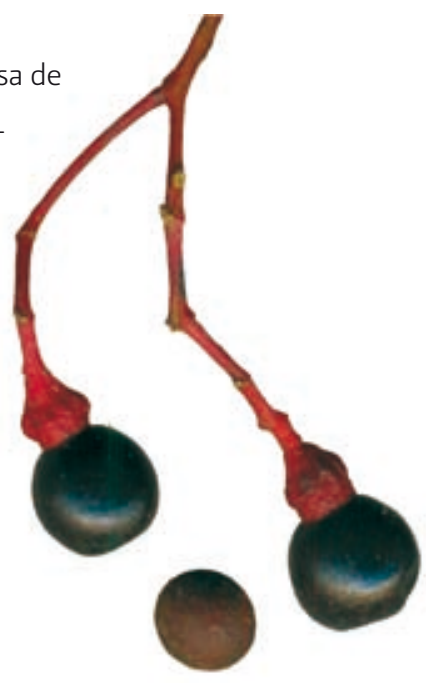




\section{Acacia cornigera (L.) Willd. Leguminosae (Mimosoideae)}

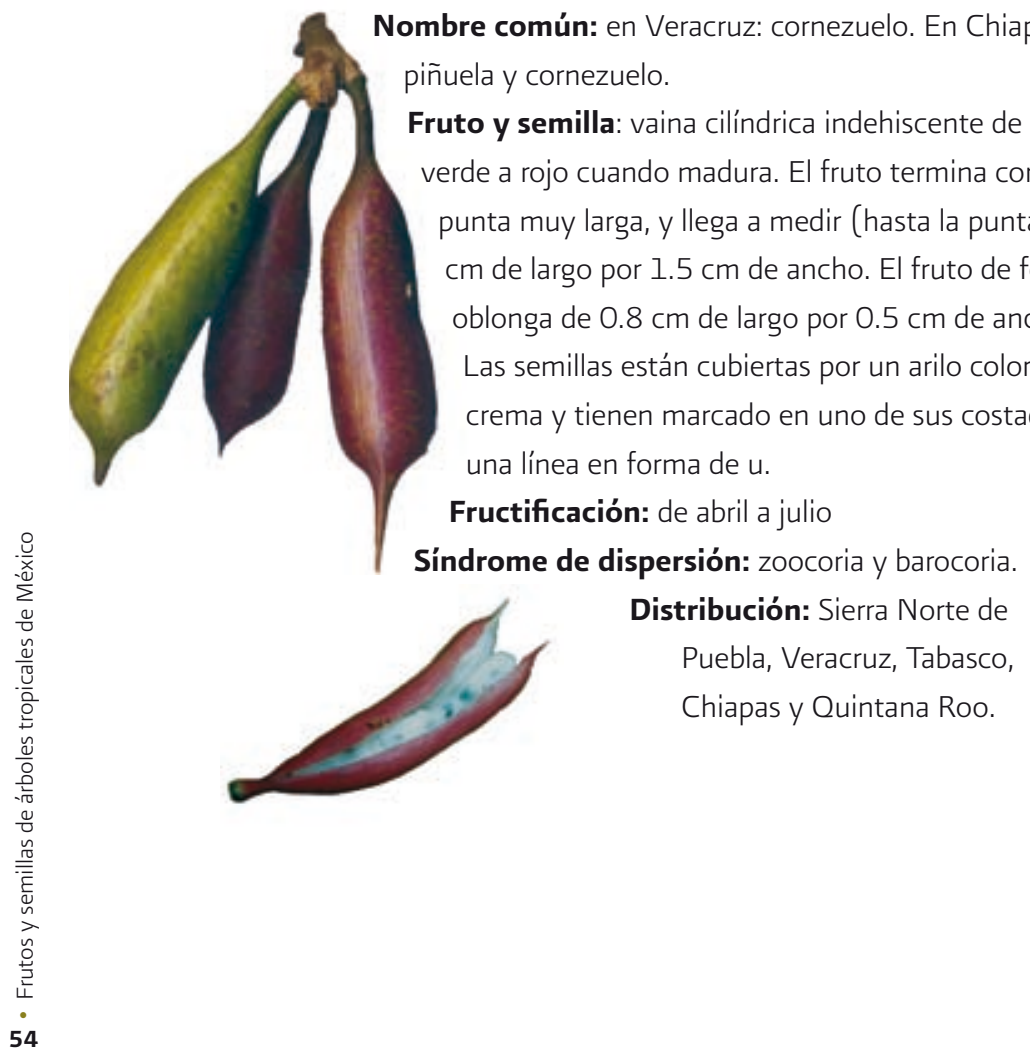




\section{Albizia leucocalyx Standley Leguminosae (Mimosoideae)}

Nombre común: guaciban.

Fruto y semilla: vaina dehiscente leñosa de color café oscuro que mide hasta $10 \mathrm{~cm}$ de largo por $3 \mathrm{~cm}$ de ancho. Contiene numerosas semillas oblongas alargadas de color crema, que alcanzan hasta $1.3 \mathrm{~cm}$ de largo por $0.4 \mathrm{~cm}$ de ancho. Se observa en la semilla un aro claro en cada costado.

Fructificación: de junio a octubre.

Síndrome de dispersión: barocoria.

Distribución: sur de Veracruz, Tabasco y Chiapas.

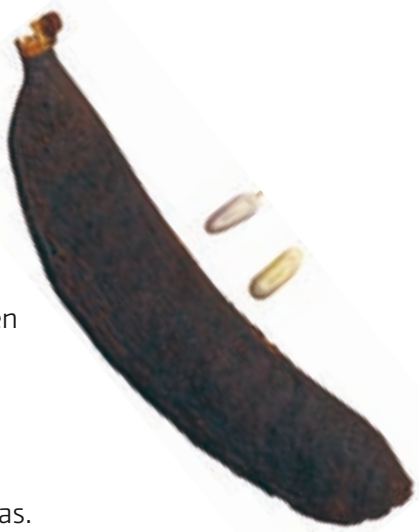




\section{Albizia purpusii Britton et Rose Leguminosae (Mimosoideae)}

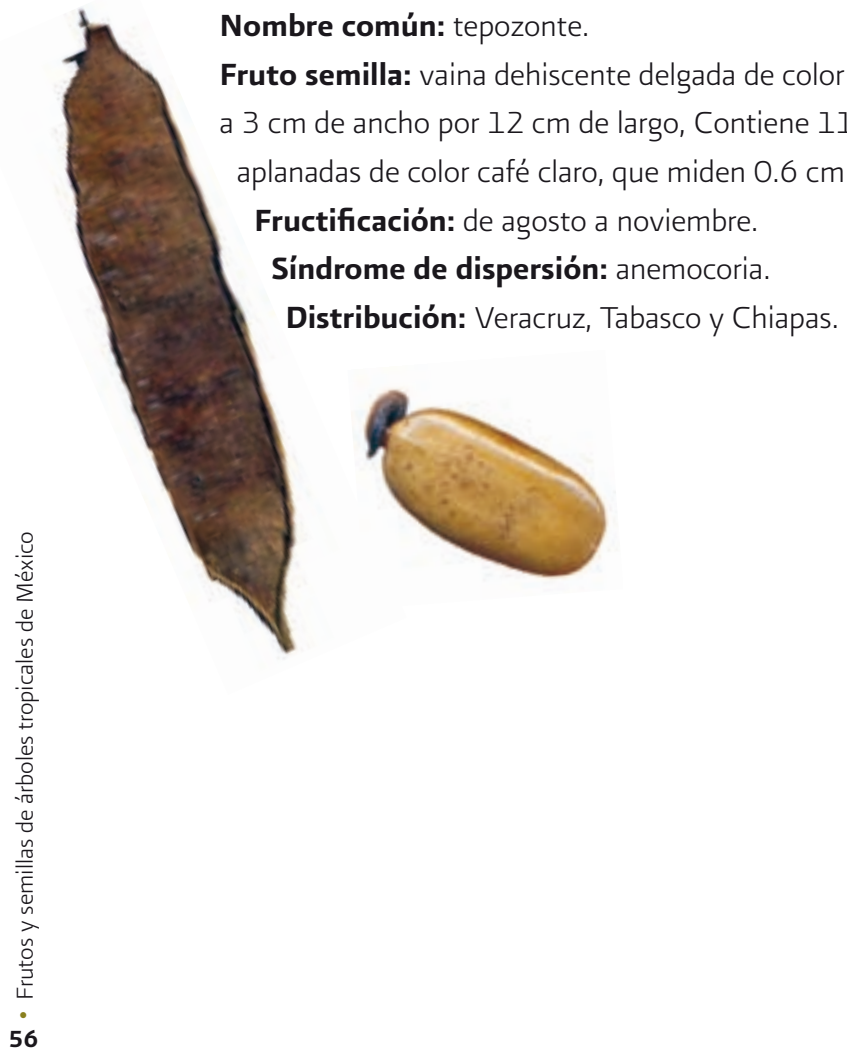




\section{Andira galeottiana StandI. Leguminosae (Faboideae)}

Nombre común: macayo.

Fruto y semilla: vaina elipsoide leñosa, reniforme, indehiscente de color verde a café cuando madura. La textura es rugosa. El fruto mide $6 \mathrm{~cm}$ de diámetro por $7 \mathrm{~cm}$ de largo, con una línea central que lo rodea. Tiene una semilla globosa, de color blanco envuelta por un pericarpio papiráceo, que alcanza hasta $4 \mathrm{~cm}$ de diámetro.

Fructificación: de agosto a diciembre. Síndrome de dispersión: zoocoria y barocoria.
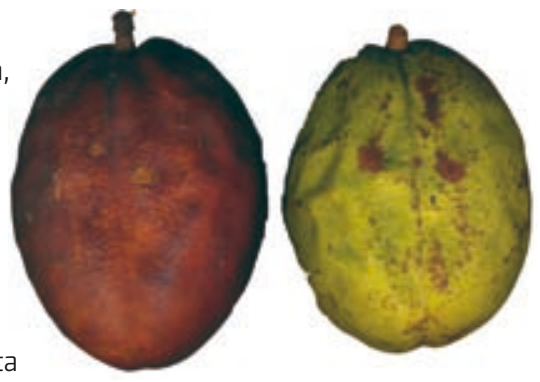

Distribución: sur de Veracruz, Tabasco, este de Oaxaca y sureste de Chiapas.

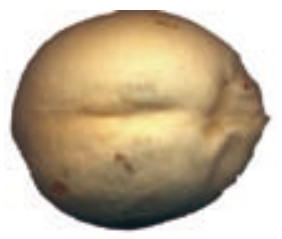




\section{Cojoba arborea (L.) Britton \& Rose Leguminosae (Mimosoideae)}

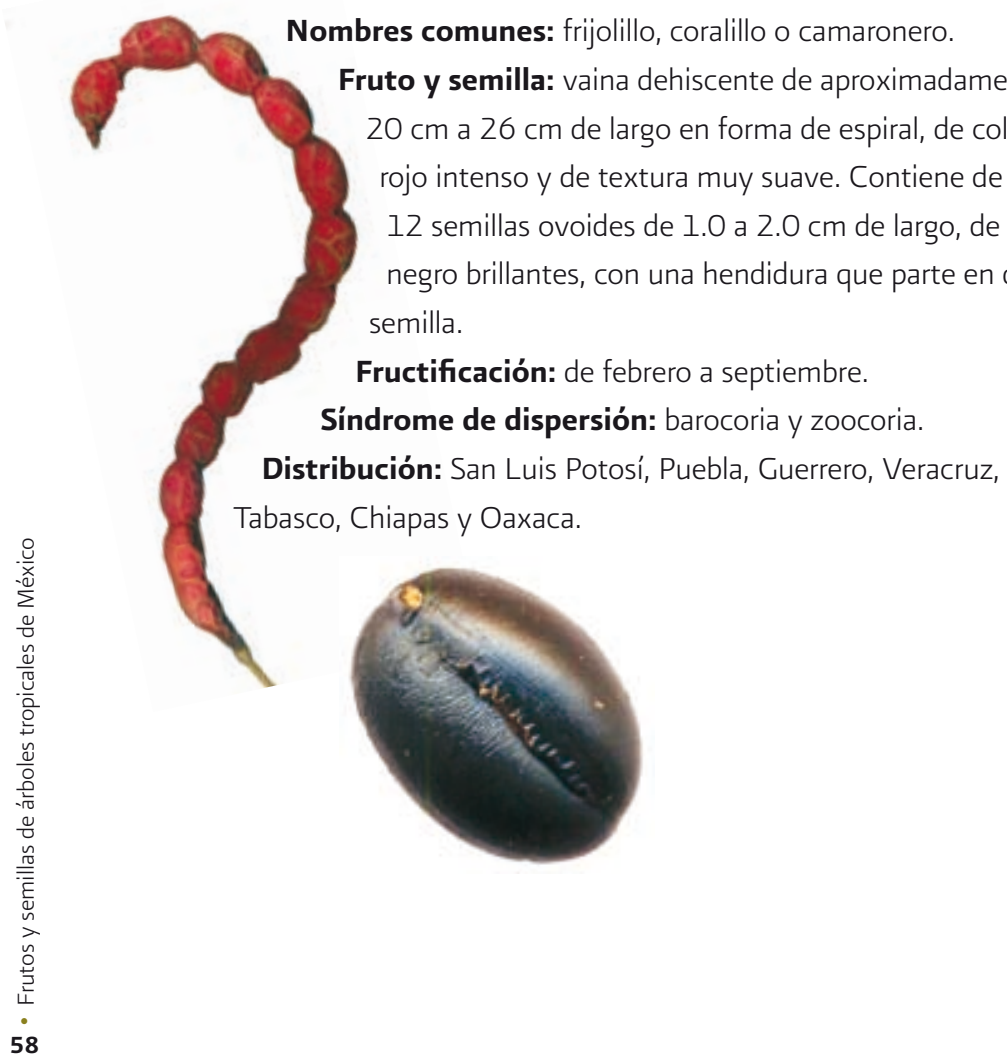




\section{Cynometra retusa Britt. \& Rose Leguminosae (Caesalpinioideae)}

Fruto y semilla: vaina indehiscente de consistencia dura de forma globosa, de color café con lenticelas de color claro; mide $2.6 \mathrm{~cm}$ de diámetro. Contiene una semilla de forma esférica, de color café, de $1.8 \mathrm{~cm}$ de diámetro.

Fructificación: de octubre a diciembre.

Síndrome de dispersión:

barocoria.

Distribución: Veracruz, Tabasco y Chiapas.

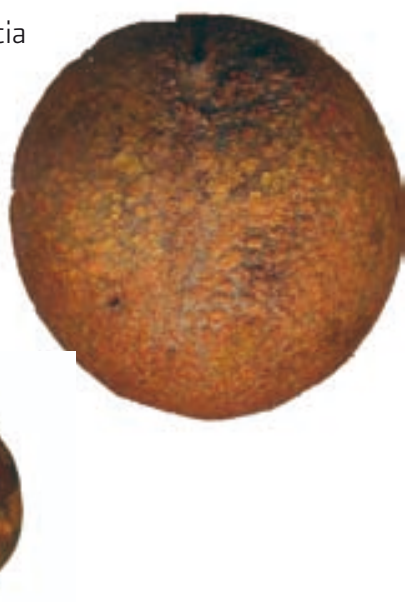




\section{Dialium guianense (Aub) Sandw. Leguminosae (Caesalpinioideae)}

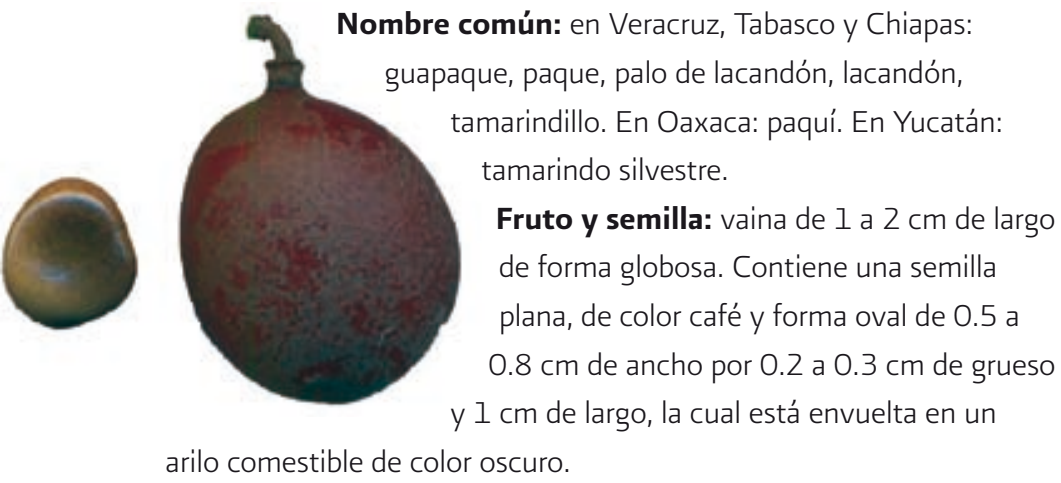

Fructificación: de marzo a junio.

Síndrome de dispersión: barocoria y zoocoria.

Distribución: Veracruz, desde la zona de los Tuxtlas, Tabasco, norte de Chiapas, Oaxaca Campeche, Quintana Roo y Yucatán. 


\section{Enterolobium cyclocarpum (Jacq.) Griseb Leguminosae (Mimosoideae)}

Nombre común: guanacaste, nacaste, parota y orejón.

Frutos y semillas: vaina indehiscente de 7 a $10 \mathrm{~cm}$ de diámetro, de color café oscuro en forma de u. Contiene numerosas semillas de forma ovoide de color café, con un aro más claro y una mancha oscura en la parte central, que miden de 2 a $3 \mathrm{~cm}$ de diámetro.

Fructificación: de abril a julio.

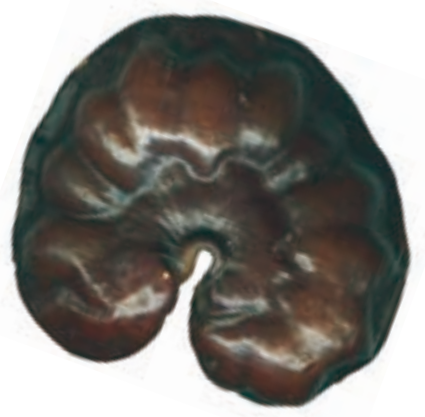

Síndrome de dispersión: barocoria y zoocoria. Distribución: en la vertiente del Golfo de México, desde Tamaulipas hasta la Península de Yucatán, y en el Pacífico, desde Sinaloa hasta Chiapas.

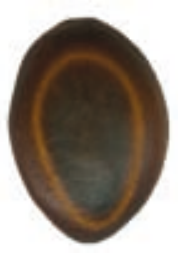




\section{Erythrina folkersii Krukoff \& Moldence Leguminosae (Faboideae)}

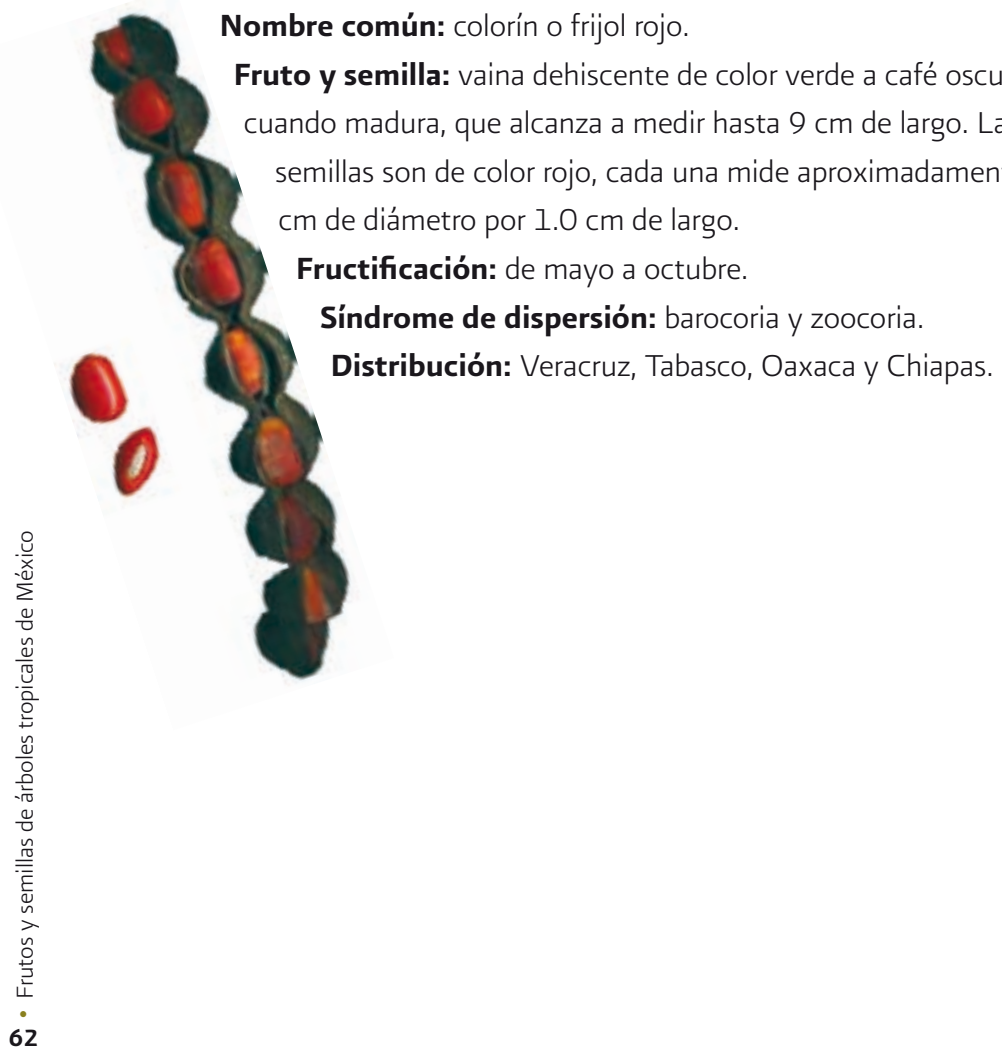




\section{Gliricidia sepium (Jacq.) Steud. Leguminosae (Faboideae)}

Nombre común: en Sinaloa, Nayarit,

Michoacán, Guerrero y Oaxaca: cacahuananche. En

Puebla, Veracruz y Oaxaca: cocoíte, cocuite. En Jalisco y Chiapas: madre de cacao. En Chiapas: yaité. En el Estado de México: frijolillo.

Fruto y semilla: vaina aplanada dehiscente de $15 \mathrm{~cm}$ a 20 $\mathrm{cm}$ de largo y $2 \mathrm{~cm}$ a $3 \mathrm{~cm}$ de ancho, de color verde amarillento. El fruto contiene hasta 15 semillas ovales y aplanadas, de 1 a $1.5 \mathrm{~cm}$ de diámetro, de color café oscuro y brillantes. Fructificación: de abril a julio.

Síndrome de dispersión: barocoria.

Distribución: por el Golfo de México, desde Tamaulipas hasta la Península de Yucatán, Isla de Cozumel, y en la vertiente del Pacífico, desde Sinaloa hasta Chiapas.

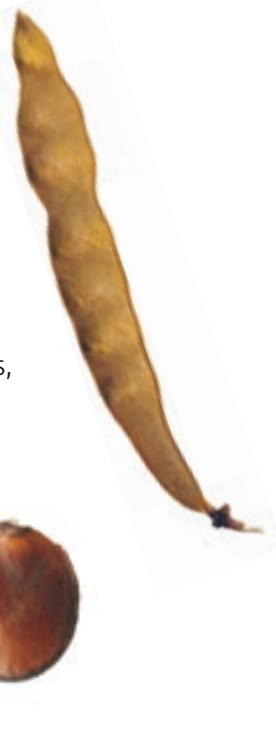




\section{Hymenaea courbaril L. Leguminosae (Caesalpinioideae)}

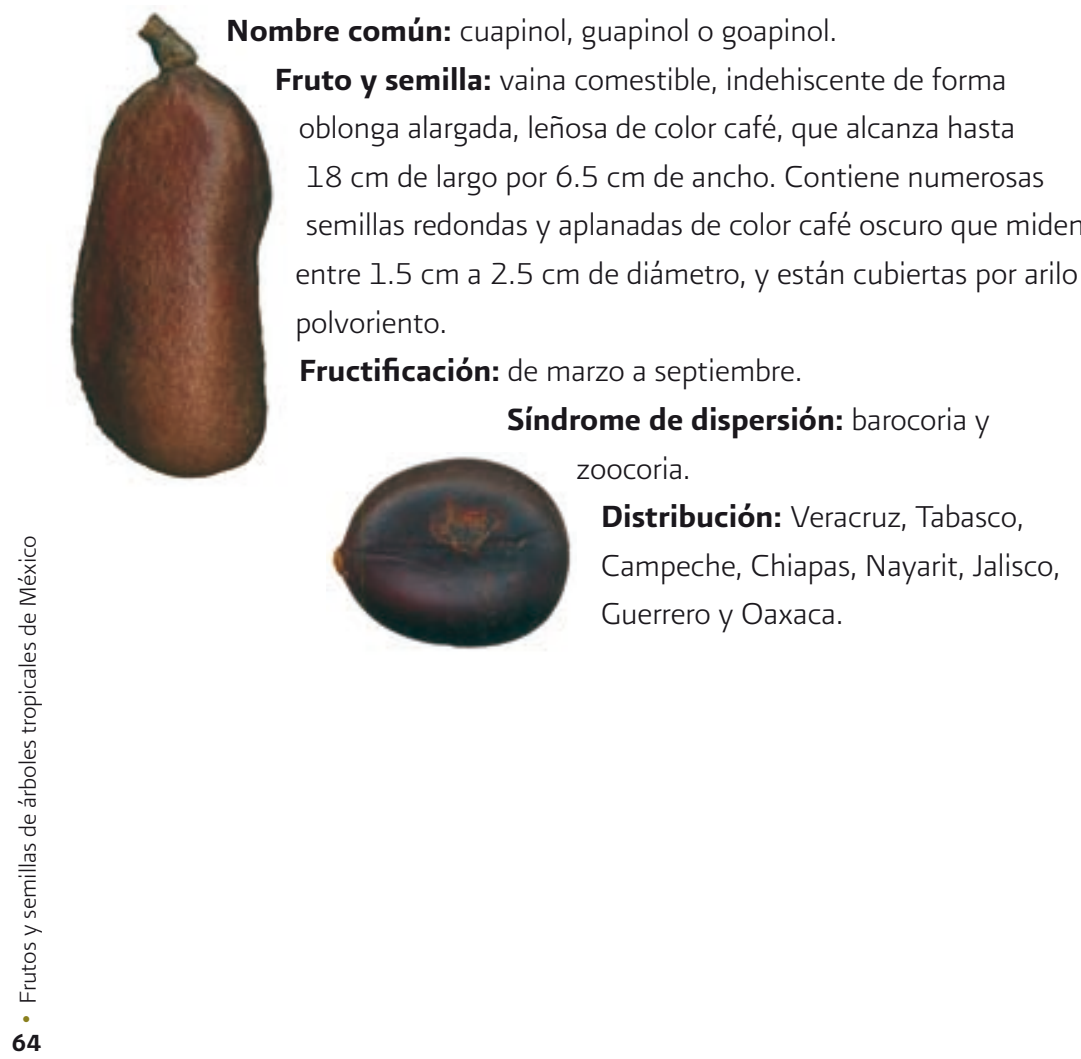




\section{Inga pavoniana Don Leguminosae (Mimosoideae)}

Nombre común: vaina o guatope.

Fruto y semilla: vaina comestible indehiscente de forma cuadrada alargada y de color verde que mide de $10 \mathrm{~cm}$ a $15 \mathrm{~cm}$ de largo. Las semillas son de color negro, cubiertas con arilo de color blanco, y alcanzan hasta $2 \mathrm{~cm}$ de largo. En ellas se observa una ranura en la parte basal en forma de cruz.

Fructificación: de enero a diciembre.

Síndrome de dispersión: zoocoria.

Distribución: Nayarit, Guerrero, Puebla, Veracruz, Tabasco y Chiapas.
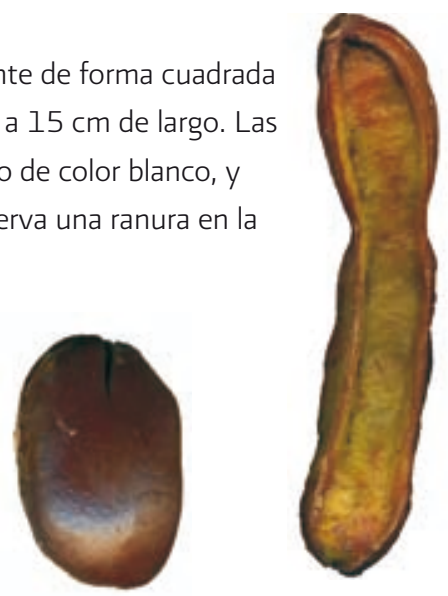


\section{Inga vera Willd. Leguminosae (Mimosoideae)}

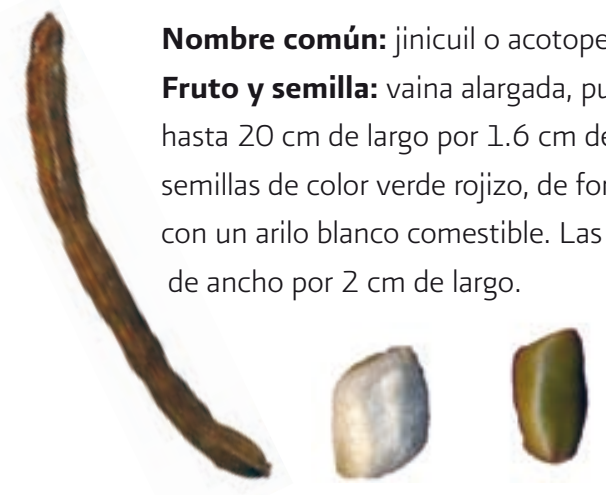

Fructificación: de agosto a octubre.

Síndrome de dispersión:

zoocoria.

Distribución: En el Golfo de México, desde Tamaulipas, San Luis Potosí, hasta Campeche, Quintana Roo y Chiapas. En la vertiente del Pacífico, desde Nayarit hasta Chiapas. 


\section{Leucaena macrophylla ssp. nelsonii (Britton et Rose) Zárate Leguminosae (Mimosoideae)}

Nombre común: guajillo.

Fruto y semilla: vaina papiracea dehiscente, de aproximadamente $15 \mathrm{~cm}$ de largo por $1.8 \mathrm{~cm}$ de ancho, y color café claro. El fruto puede tener de 25 a 30 semillas de forma oblonga y de color café oscuro. Las semillas presentan en uno de sus lados un piquito. Miden hasta $0.8 \mathrm{~cm}$ de largo por 0.5 de ancho.

Fructificación: de septiembre a noviembre.

Síndrome de dispersión: barocoria.

Distribución: en la vertiente del Pacífico, se extiende por los estados de Nayarit, Jalisco, Michoacán, Guerrero y Oaxaca. En el Golfo de México, se halla exclusivamente en la región de los Tuxtlas, Veracruz.

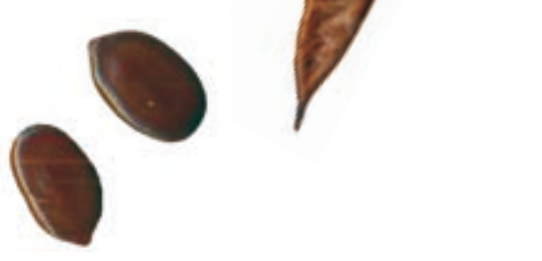




\section{Lonchocarpus rugosus Benth. Leguminosae (Faboideae)}

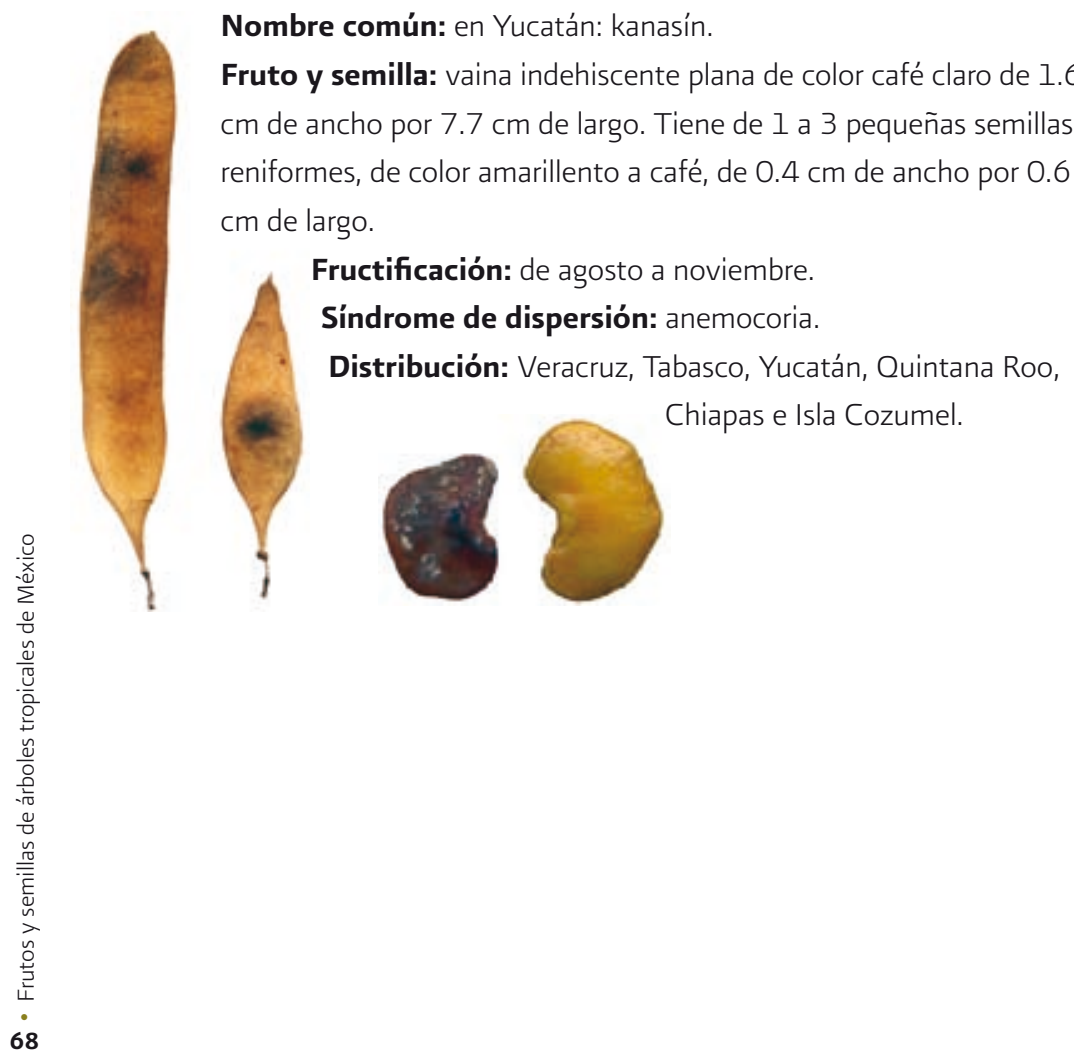




\section{Platymiscium yucatanum Stand Leguminosae (Faboideae)}

Nombre común: en Campeche, Quintana Roo, Yucatán y Chiapas: granadillo. En Chiapas: marimbo, hormiguillo. En Veracruz: chagane.

Fruto y semilla: vaina indehiscente alada de color café y de forma oblonga alargada, que mide hasta $8 \mathrm{~cm}$ de largo por $3 \mathrm{~cm}$ de ancho. Contiene una semilla oblonga alargada, de color café claro, en uno de cuyos lados se observa un canal circular. La semilla mide $2 \mathrm{~cm}$ de largo por $1 \mathrm{~cm}$ de ancho.

Fructificación: de mayo a agosto.

Síndrome de dispersión: anemocoria.

Distribución: Chiapas y la Península de Yucatán.

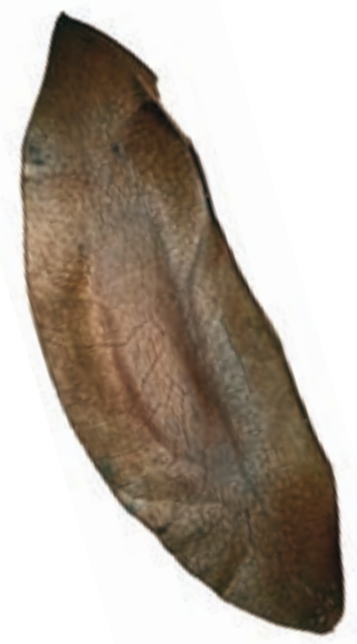




\section{Pterocarpus rohrii Vahl Leguminosae (Faboideae)}

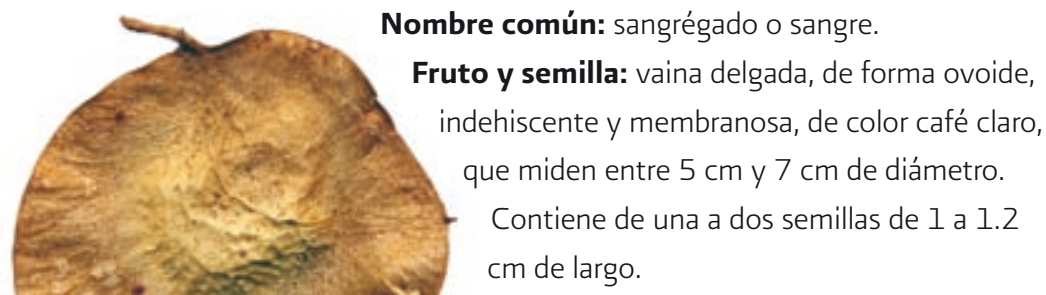

Fructificación: de agosto a noviembre.

Síndrome de dispersión: anemocoria.

Distribución: Veracruz, Tabasco, Oaxaca, Chiapas y Quintana Roo. 


\section{Schizolobium parahyba (Vell.) Blake Leguminosae (Caesalpinioideae)}

Nombre común: en Veracruz y Oaxaca: palo de picho.

En el sur de Veracruz: palo de judío. En Chiapas: lacandón, cuchillal, plumillo y guanacaste.

Fruto y semilla: vaina aplanada dehiscente de $9 \mathrm{~cm}$ a 10 $\mathrm{cm}$ de largo por $2.5 \mathrm{~cm}$ a $3.5 \mathrm{~cm}$ de ancho. Contiene una semilla alada de aproximadamente $0.8 \mathrm{~cm}$ de diámetro, redonda, aplanada y de color oscuro.

Fructificación: de abril a junio.

Síndrome de dispersión: anemocoria.

Distribución: centro de Veracruz, Chiapas, Tabasco y norte de Oaxaca.
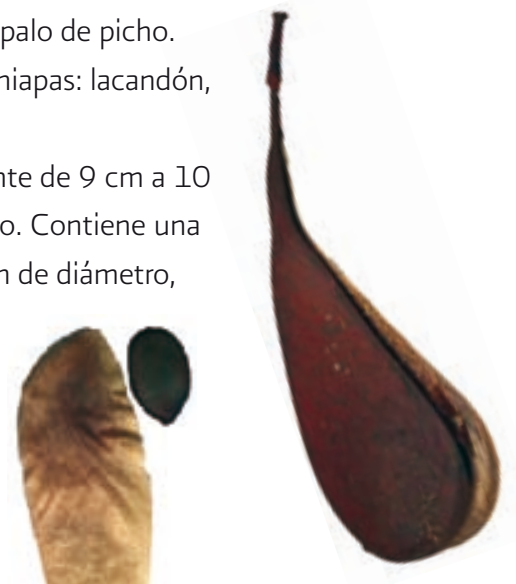


\section{Swartzia guatemalensis (Donn.Sm) Pittie Leguminosae (Faboideae)}

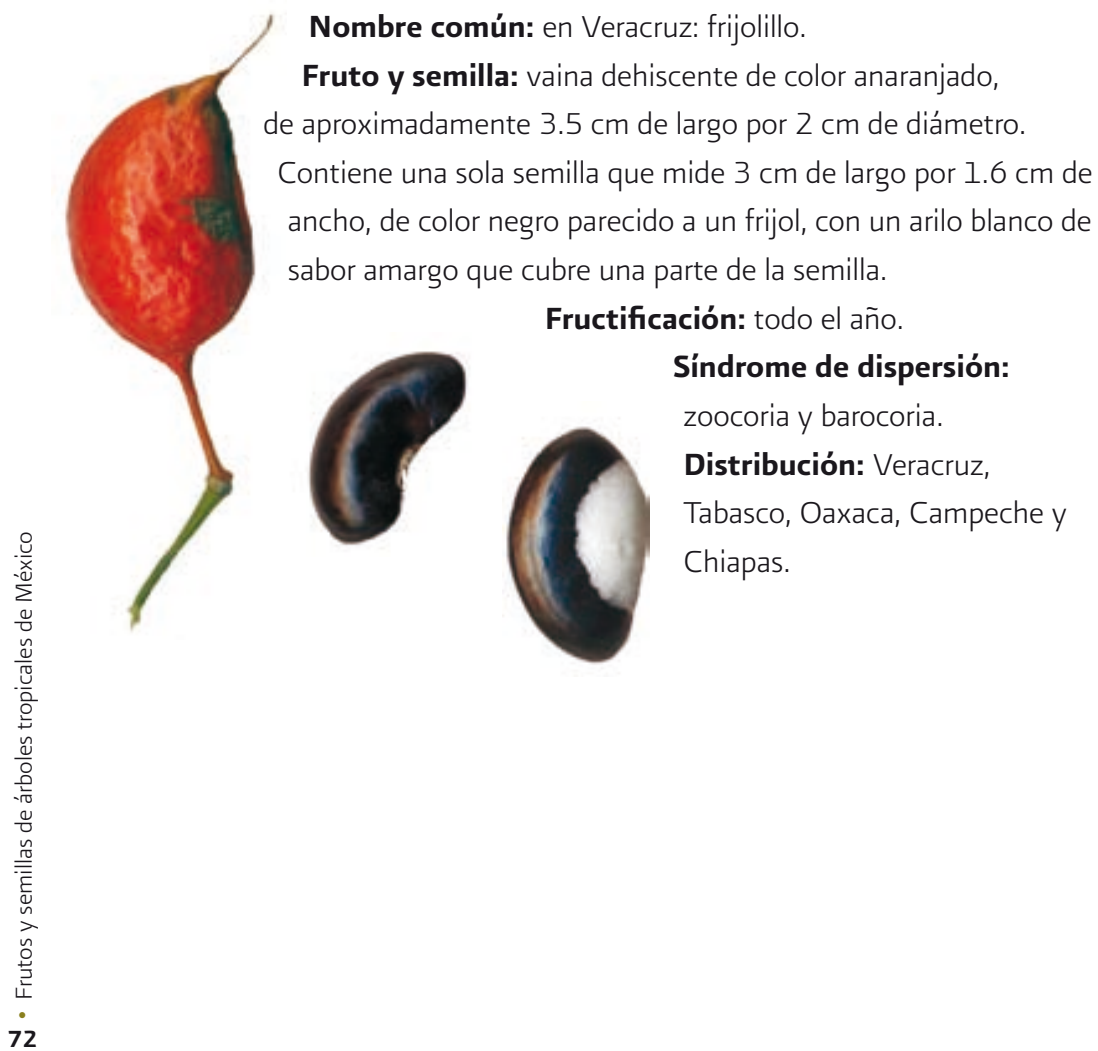




\section{Vatairea lundellii (Standley) Killip ex Record Leguminosae (Faboideae)}

Nombre común: amargoso y picho.

Fruto y semilla: diaspora alada indehiscente de color

café, de aproximadamente $10 \mathrm{~cm}$ de largo. El fruto tiene una sola semilla aplanada de $1.5 \mathrm{~cm}$ de diámetro de color crema.

Fructificación: de bril a mayo.

Síndrome de dispersión: anemocoria.

Distribución: Veracruz, Tabasco, sureste de Oaxaca, Chiapas y Campeche.

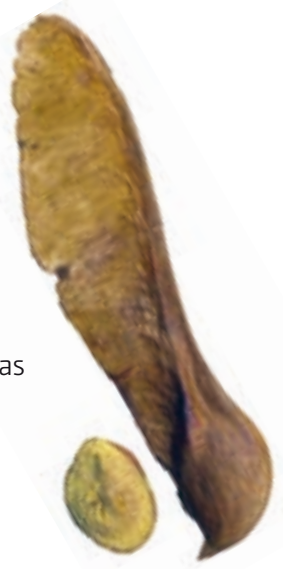




\section{Talauma mexicana (DC.) Don. Magnoliaceae}

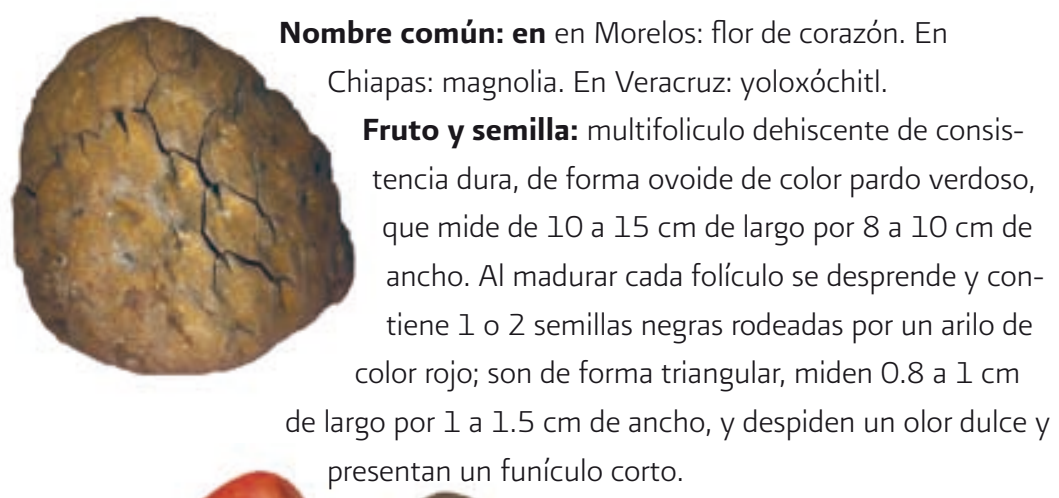

Fructificación: de mayo a abril.

Síndrome de dispersión: zoocoria, barocoria.

Distribución: en la vertiente del Golfo de México, desde el norte de Puebla y Veracruz hasta el norte de Chiapas. En la vertiente del Pacífico, en Guerrero y Oaxaca. 


\section{Hampea nutricia Fryxell Malvaceae}

Nombre común: en Veracruz: jonote blanco, tecolixtle. En Tabasco y Oaxaca: mjagua de ratón, majagua. En Chiapas: jonote blanco, majagua.

Fruto y semillas: cápsula dehiscente de forma elíptica trivalvada, de entre 1.5 a $2.5 \mathrm{~cm}$ de largo, de color verde grisáceo, con arilo blanco. Tiene una cúpula café que sostiene al fruto. Las semillas son de forma oblonga, de color negro, y miden entre 0.3 y $0.7 \mathrm{~cm}$ de diámetro, con una cicatriz de color claro.

Fructificación: febrero a mayo.

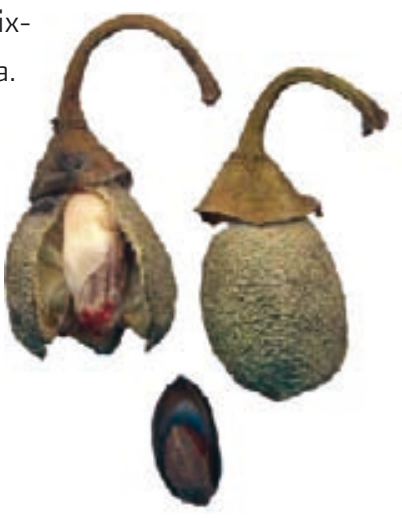

Síndrome de dispersión: zoocoria.

Distribución: Sierra Norte de Puebla, Veracruz, Tabasco y norte de Chiapas. 


\section{Robinsonella mirandae Gómez-Pompa Malvaceae}

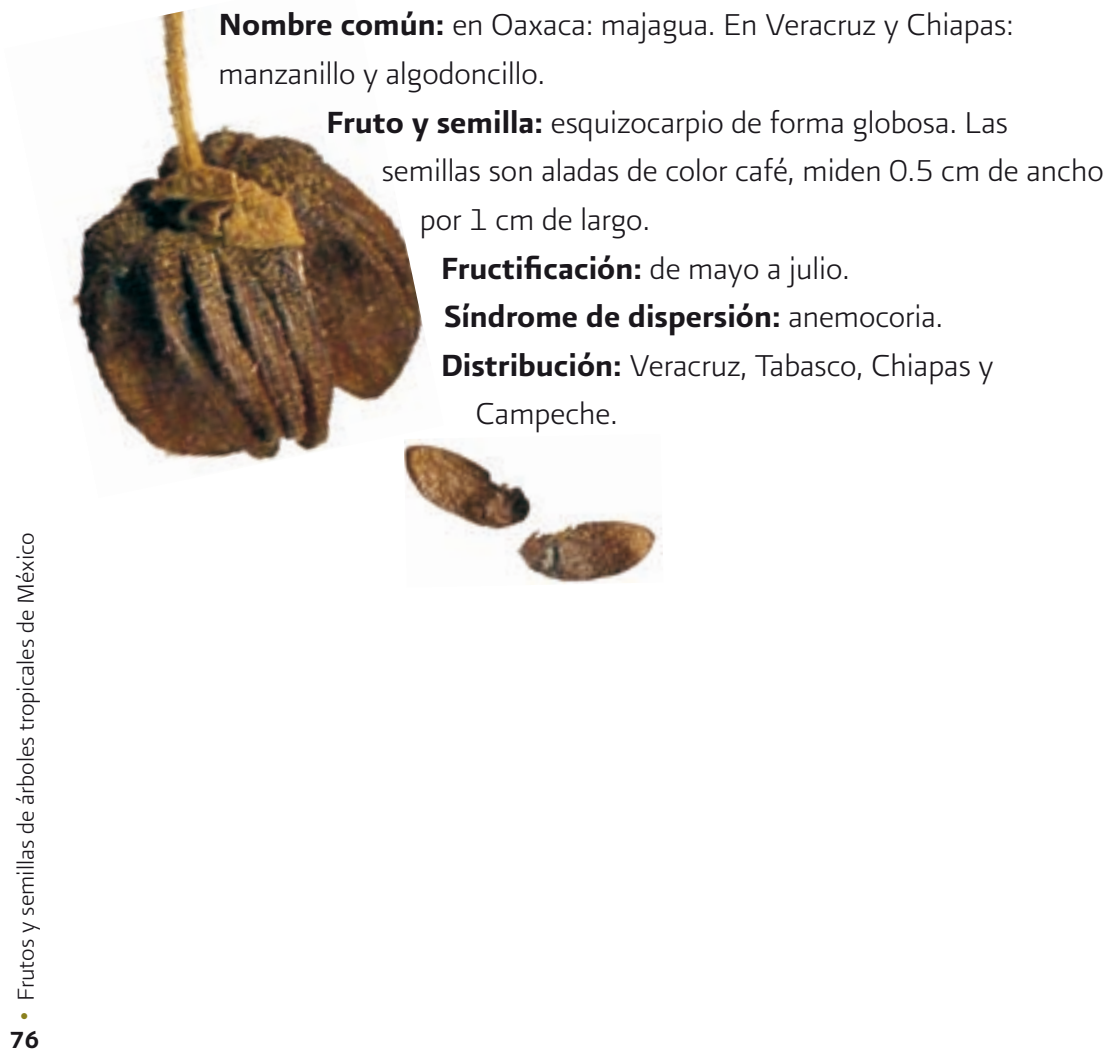




\section{Bellucia grossularioides (L.) Triana Melastomataceae}

Nombre común: En Chiapas: duraznillo o manzanita. En Veracruz y Tabasco; manzanita o manzano.

Fruto y semilla: baya globosa que mide hasta $4 \mathrm{~cm}$ de diámetro de color amarillo claro. El fruto tiene una apariencia de pico de loro, con numerosas semillas globosas muy pequeñas menores a $0.1 \mathrm{~cm}$ de diámetro.

Fructificación: de marzo a diciembre.

\section{Síndrome de dispersión:}

zoocoria.

Distribución: Veracruz, Tabasco

y Chiapas.
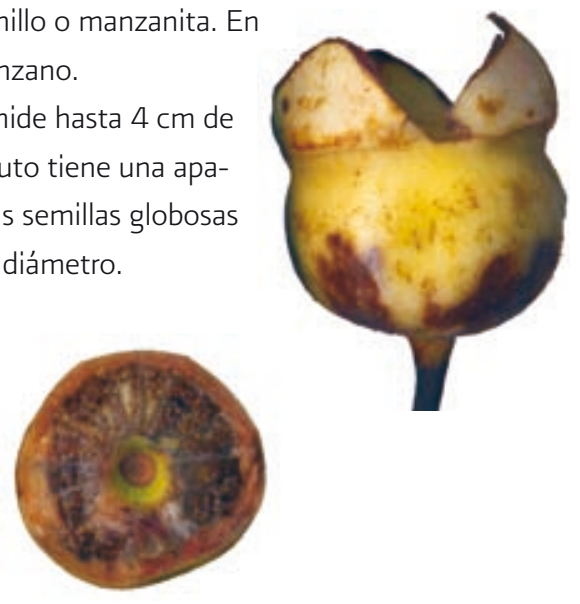


\section{Miconia argentea (Sw.) DC. Melastomataceae}

Nombre común: en Oaxaca y Veracruz: hoja de lata, tecalate, yagaguito, cenizo. En Campeche: cuero de vaca. En Tabasco: cenizo, sabano. En Chiapas: manzano.

Fruto y semilla: baya globosa un poco aplanada de $0.8 \mathrm{~cm}$ de diámetro por $0.4 \mathrm{~cm}$ de altura de color morado; presenta partes florales (cáliz) en una de sus extremos. Cada fruto contiene numerosas semillas muy pequeñas de $0.1 \mathrm{~cm}$ de diámetro de color crema.

Fructificación: de julio a noviembre.

Síndrome de dispersión: zoocoria.

Distribución: Veracruz, Tabasco, Campeche, norte de Oaxaca, Chiapas, sur de Quintana Roo. 


\section{Cedrela odorata $\mathrm{L}$ Meliaceae}

Nombre común: cedro.

Fruto y semilla: cápsula elipsoide dehiscente con olor a ajo, abre en cuatro o cinco valvas. Presenta numerosas lenticelas de color café claro. El fruto contiene entre 25 y 30 semillas aladas que, incluyendo el ala, llegan a medir hasta $2.5 \mathrm{~cm}$ de largo.

Fructificación: de febrero a mayo. Síndrome de dispersión: anemocoria.

Distribución: por el Golfo de México, desde Tamaulipas hasta Yucatán, Quintana Roo e Isla Cozumel. En el Pacifico, desde Sinaloa hasta Chiapas.
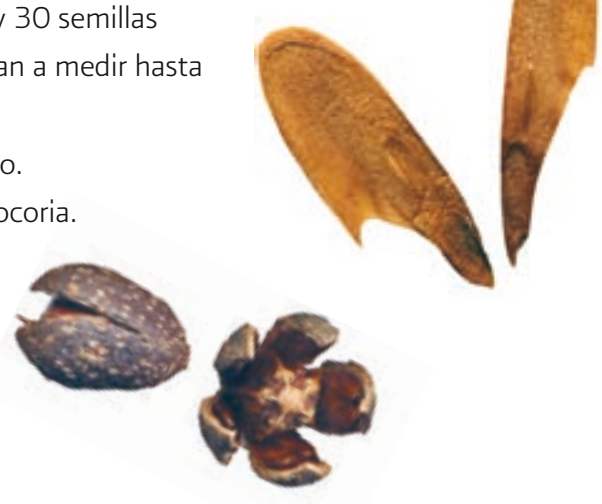


\section{Guarea glabra Vahl Meliaceae}

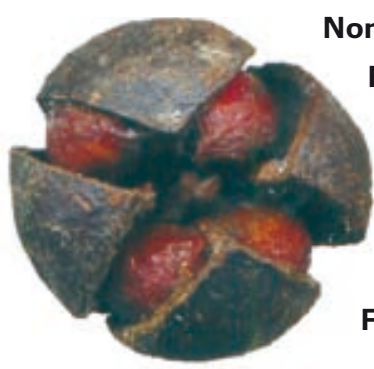

Fruto y semilla: cápsula dehiscente de forma globosa de color rojo a café oscuro. Abre en 4 valvas, y mide entre 1.5 y $Z \mathrm{~cm}$ de diámetro. Contiene de $Z$ a 4 semillas de color crema de aproximadamente 1 cm de largo, cubiertas por un arilo color rojo.

Fructificación: de abril a junio.

Síndrome de dispersión: zoocoria y

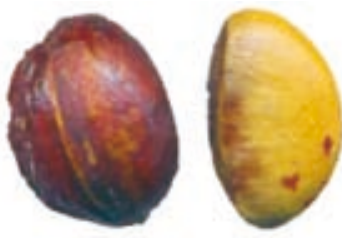
barocoria.

Distribución: Puebla, Veracruz, Tabasco, Campeche, Quintana Roo, Chiapas. Y por la vertiente del Pacífico, Nayarit, Colima, Jalisco, Guerrero y Oaxaca. 


\section{Guarea grandifolia DC. Meliaceae}

Nombre común: en Veracruz: sabino.

Fruto y semilla: cápsula dehiscente en forma de pera, de color marrón, de $6.3 \mathrm{~cm}$ de diámetro por $10 \mathrm{~cm}$ de largo. Se abre en 4 a 8 valvas; por lóbulo contiene de 1 a 2 semillas de color café, envueltas con arilo rojizo, que miden $1.5 \mathrm{~cm}$ de ancho por $2.2 \mathrm{~cm}$ de largo.

Fructificación: de diciembre a junio.

Síndrome de dispersión: zoocoria.

Distribución: Sierra Norte de Puebla, Chiapas y

Veracruz.
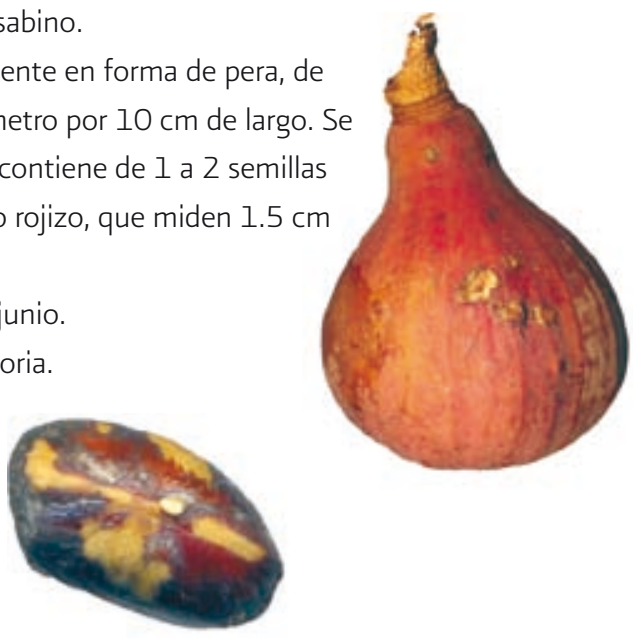


\section{Swietenia macrophylla King Meliaceae}

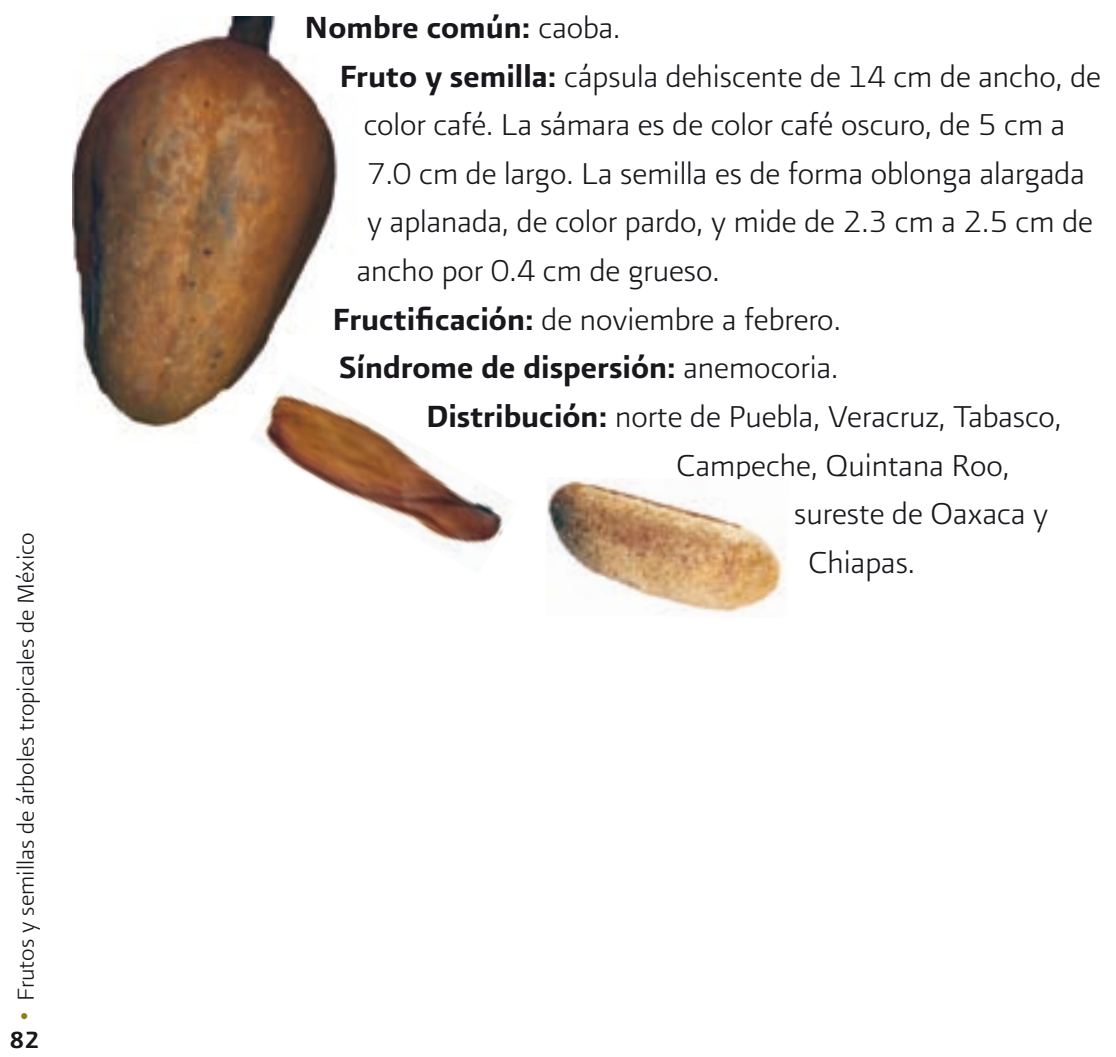




\section{Trichilia havanensis Jacq. Meliaceae}

Nombre común: en Oaxaca: limoncillo. En Tamaulipas: cucharillo. En Colima: garrapatilla. En Sinaloa: cauache. En Hidalgo, Puebla, San Luis Potosí y Veracruz: palo de cuchara. En Chiapas: coshigüe.

Fruto y semilla: cápsula dehiscente de forma globosa, de $0.8 \mathrm{~cm}$ de diámetro, de color verde oscuro. Contiene de 2 a 4 semillas de forme ovoide, de color café, envueltas en un arilo que cambia de blanco a rojo conforme maduran; miden $0.5 \mathrm{~cm}$ de largo.

Fructificación: de mayo a octubre.

Síndrome de dispersión: zoocoria.

Distribución: Tamaulipas, San Luis Potosí, Sierra Norte de Puebla, Veracruz, Tabasco, Campeche, Sinaloa, Nayarit, Jalisco, Guerrero, Michoacán, Oaxaca y Chiapas. 


\section{Brosimum alicastrum Sw. Moraceae}

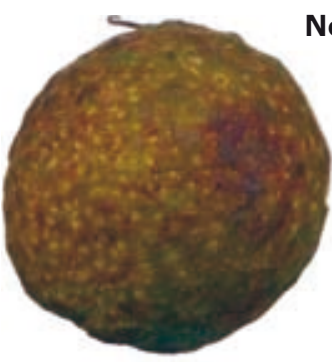

Nombre común: ramón, ojoche y osch.

Fruto y semilla: baya globosa y carnosa. Mide aproximadamente $2.5 \mathrm{~cm}$ de diámetro, y es de color verde amarillento a rojizo cuando está madura. Cada fruto tiene una o dos semillas de $2 \mathrm{~cm}$ de diámetro, cubiertas por una testa papirácea.

Fructificación: de marzo a junio.

Síndrome de dispersión: zoocoria.

Distribución: en la vertiente del

Golfo de México, va desde

Tamaulipas a Yucatán. También se halla en la región del Caribe, en Quintana Roo y en el Pacífico, desde Sinaloa hasta Chiapas. 


\section{Castilla elastica Cerv. Moraceae}

Nombre común: hule o árbol del hule.

Fruto y semilla: fruto (falso) compuesto por drupas agregadas, que en conjunto tienen aspecto de un fruto de forma ovoide de color anaranjado. El fruto termina en picos, mide de 3 a $5 \mathrm{~cm}$ de diámetro. Las semillas son de forma oblonga de color claro, de 0.8 a 1 cm de largo, se observa en ellas una línea tenue de color más oscuro que las rodea.

Fructificación: de julio a octubre.

Síndrome de dispersión: zoocoria.

Distribución: San Luis Potosí,

Puebla, Veracruz, Tabasco,

Campeche, Quintana Roo, Chiapas y

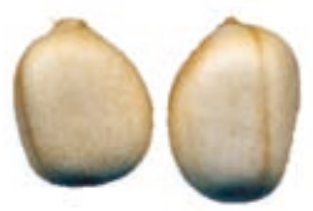

Oaxaca.

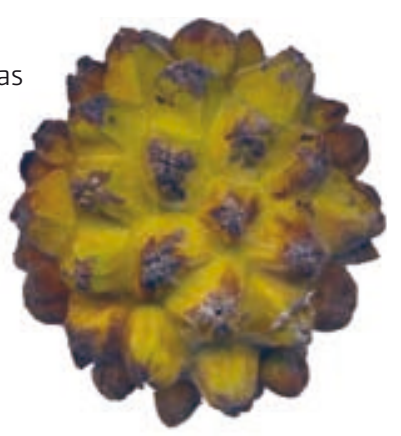




\section{Ficus maxima Mill. Moraceae}

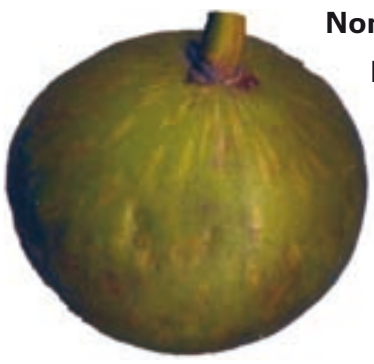

Nombre común: amate.

Fruto y semilla: sicono carnoso y áspero, de forma globosa y de color verde. Presenta manchas blancas alrededor; mide de 4 a $4.5 \mathrm{~cm}$ de diámetro, y en su interior se observan numerosas drupas redondas, de menos de $0.1 \mathrm{~cm}$ de diámetro, cada una de las cuales contiene una semilla sumamente pequeña.

Fructificación: todo el año. Síndrome de dispersión: zoocoria.

Distribución: Nayarit, Veracruz, Chiapas, Isla Cozumel y Quintana Roo. 


\section{Poulsenia armata (Miq.) Standl. Moraceae}

Nombre común: en Veracruz y Chiapas: abasbabi, agabasgabi, chirimoya. En Oaxaca: chichicastle o carnero blanco.

Fruto y semilla: el fruto lo conforman pequeñas drupas agregadas, mide de 4 hasta 6 $\mathrm{cm}$ de diámetro, y es de color verde oscuro a naranja cuando madura. Contiene numerosas semillas de forma ovoide de 1 a $1.5 \mathrm{~cm}$ de largo.

Síndrome de dispersión: zoocoria.

Distribución: la distribución

México se extiende desde la región

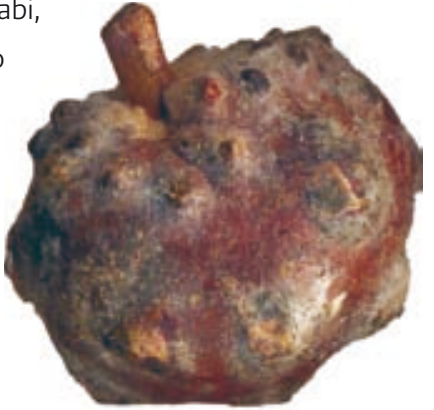
en Veracruz, hasta el noreste de Chiapas (Selva Lacandona). En la vertiente del Pacífico, en la costa de Oaxaca hasta Chiapas.

en el Golfo de de los Tuxtlas, 


\section{Trophis mexicana (Liebm.) Bureau Moraceae}

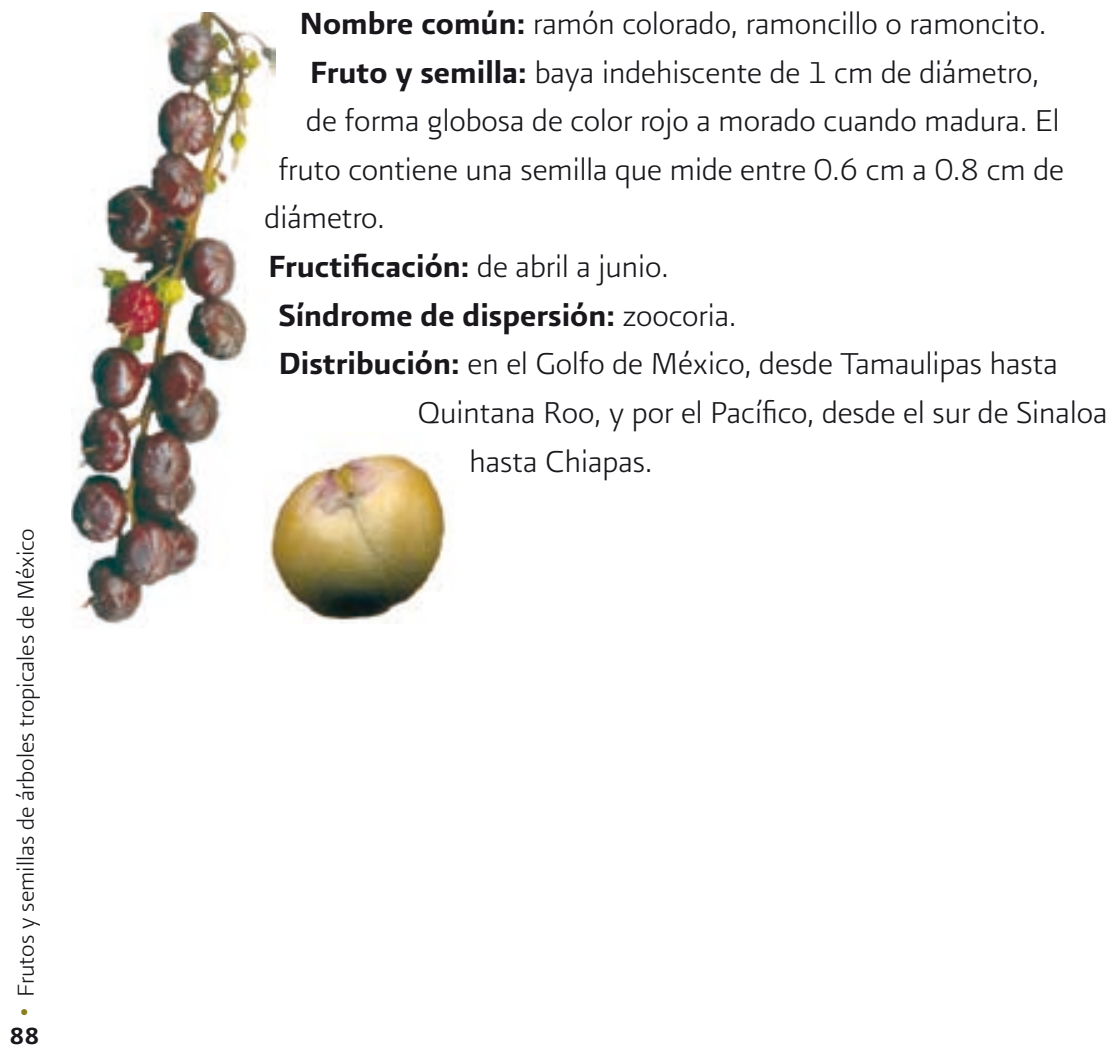




\section{Virola guatemalensis (Hemsl.) Warb. Myristicaceae}

Nombre común: en Veracruz: cedrillo. En Chiapas; cacao volador y volador.

Fruto y semilla: cápsula dehiscente bivalvada de $3 \mathrm{~cm}$ de largo por $2 \mathrm{~cm}$ de diámetro, de forma elíptica de color verde amarillento. El fruto tiene una sola semilla de color café rodeada por un arilo rojizo, que mide $2.5 \mathrm{~cm}$ de largo por $1.7 \mathrm{~cm}$ de diámetro. Fructificación: de octubre a abril. Síndrome de dispersión: zoocoria. Distribución: Veracruz, Oaxaca y Chiapas.
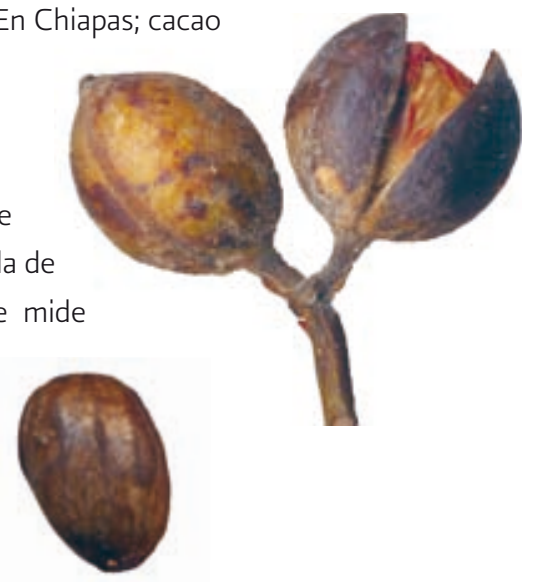


\section{Eugenia acapulcensis Steudel Myrtaceae}

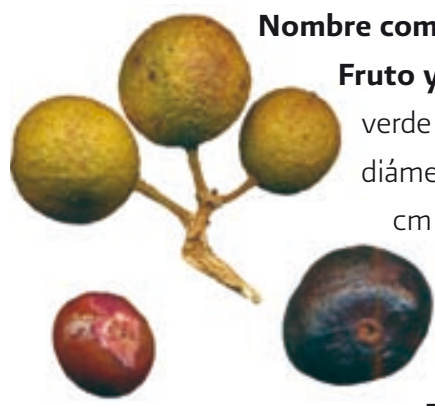

a negra cuando madura, de $1.5 \mathrm{~cm}$ a $2 \mathrm{~cm}$ de ámetro. Contiene una semilla globosa que mide 1 $\mathrm{cm}$ a $1.5 \mathrm{~cm}$ de diámetro de color café. El arilo es comestible.

Fructificación: de septiembre a diciembre. Sindrome de dispersión: zoocoria.

Distribución: Sinaloa, Nayarit, Guerrero, Tamaulipas, Veracruz, Chiapas, Campeche y la Isla Cozumel. 


\section{Pimienta dioica (L.) Merrill Myrtaceae}

Nombre común: patololote, pimienta y pimienta gorda.

Fruto y semilla: bayas redondas de color verde a negro cuando maduran; el fruto emana un fuerte olor agradable, y mide de 0.8 a $1.0 \mathrm{~cm}$ de diámetro. Contiene una semilla de forma ovoide aplanada, y en los costados se observa en ella una línea tenue en forma de u. Las semillas miden $0.3 \mathrm{~cm}$ de ancho por $0.6 \mathrm{~cm}$ de largo.

Fructificación: de junio a octubre.

Síndrome de dispersión: zoocoria.

Distribución: Veracruz, Tabasco, Oaxaca,

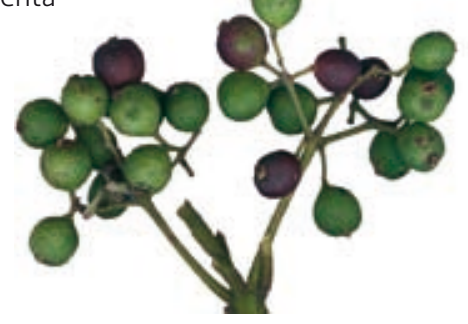
Chiapas, Campeche y Quintana Roo.

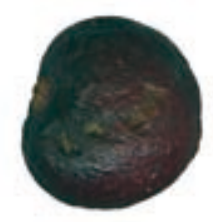




\section{Coccoloba hondurensis Lundell Polygonaceae}

Nombre común: en Veracruz: uvero. En Oaxaca: carnero. En Tabasco y Chiapas: bolchiche.

Fruto y semilla: drupa globosa, de colro rojizo, de $1 \mathrm{~cm}$ a $2 \mathrm{~cm}$ de diámetro. Contiene una semilla globosa que mide $0.5 \mathrm{~cm}$ de diámetro.

Fructificación: de diciembre a febrero.

Síndrome de dispersión: zoocoria y barocoria. Distribución: Veracruz, Chiapas, Tabasco y Oaxaca. 


\section{Calycophyllum candidissimum (Vahl) DC. Rubiaceae}

Nombre común: en Veracruz: dagame. En Chiapas: palo colorado. En Oaxaca: palo calabaza. En Guerrero, Oaxaca y Chiapas: camarón o palo de camarón.

Fruto y semilla: cápsula alargada dehiscente de color pardo, de $1 \mathrm{~cm}$ de largo por $0.3 \mathrm{~cm}$ de ancho, con numerosas semillas que miden $0.4 \mathrm{~cm}$ de largo. En algunas infrutescencias se pueden observar restos de la flor (cáliz) con apariencia de hoja. Fructificación: de enero a junio. Síndrome de dispersión: barocoria.

Distribución: Veracruz, Oaxaca, Chiapas y Campeche. 


\section{Faramea occidentalis (L.)A. Rich. Rubiaceae}

Nombre común: cafecillo.

Fruto y semilla: drupa de color rojo amari-

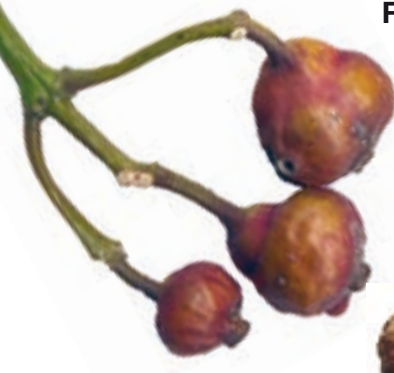
llento que mide hasta $1 \mathrm{~cm}$ de diámetro. Contiene una semilla redonda de 0.5 a 0.8 $\mathrm{cm}$ de diámetro.

Fructificación: de septiembre a febrero.

Síndrome de dispersión: zoocoria.

Distribución: Veracruz,

Tabasco y Chiapas. 


\section{Posoqueria latifolia (Rudge) R. \& S. Rubiaceae}

Nombre común: palo de peine.

Fruto y semilla: baya, de forma ovoide de color verde, que mide de 3 a $6 \mathrm{~cm}$ de diámetro, y contiene hasta 11 semillas de color blanco de consistencia suave. El fruto abierto emana un olor dulce. Las semillas tienen forma de prisma, miden $1.5 \mathrm{~cm}$ por $1 \mathrm{~cm}$ de ancho por $2 \mathrm{~cm}$ de largo, y están cubiertas por un arilo de color amarillo. Con el transcurso del tiempo las semillas adquieren un color café oscuro.

Fructificación: de junio a octubre. Síndrome de dispersión: barocoria.
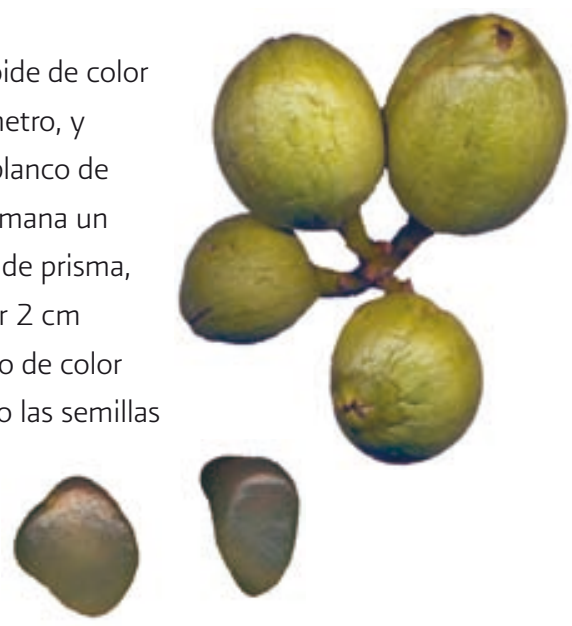

Distribución: Veracruz, Tabasco y

Chiapas. 


\section{Psychotria simiarum Standley Rubiaceae}

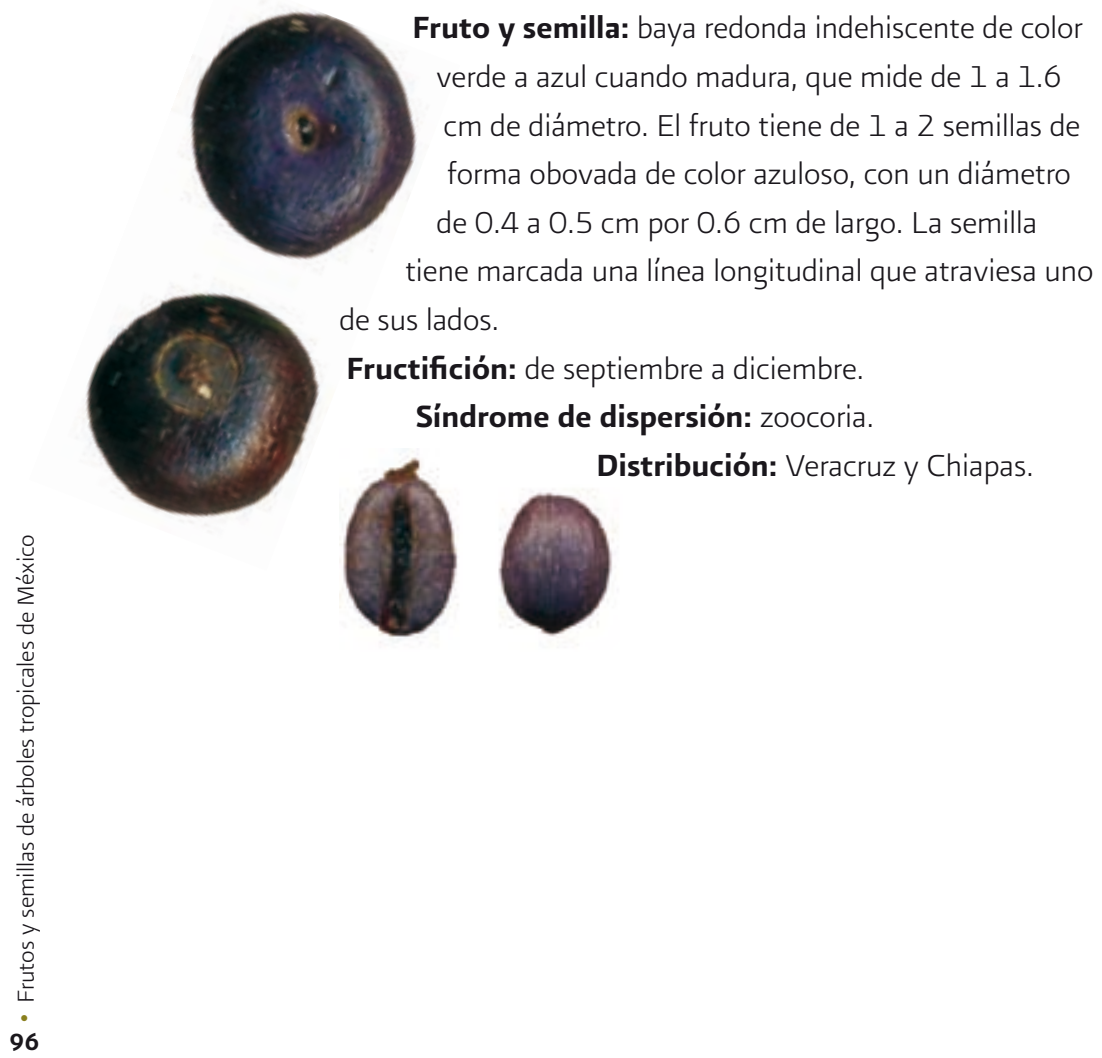




\section{Zanthoxylum caribaeum Lam. Rutaceae}

Nombre común: pochote o concha de lagarto.

Frutos y semilla: cápsula dehiscente, con forma de pera, de color verde, mide $0.7 \mathrm{~cm}$ de ancho por $0.8 \mathrm{~cm}$ de largo. Cada fruto contiene una semilla globosa cubierta de arilo. Las semilla mide $0.5 \mathrm{~cm}$ de diámetro. Los frutos crecen en grupos de 3 a 5 por ramilla.

Fructificación: de julio a septiembre.

\section{Síndrome de dispersión:}

barocoria y zoocoria.

Distribución: Jalisco,

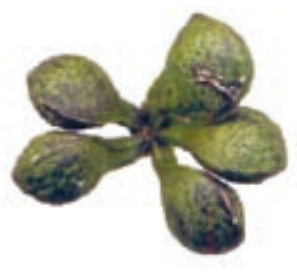

Veracruz, Tabasco, Chiapas, Campeche y

Quintana Roo.

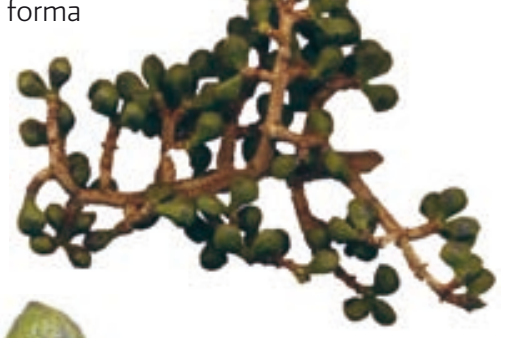




\section{Cupania glabra Sw. Sapindaceae}

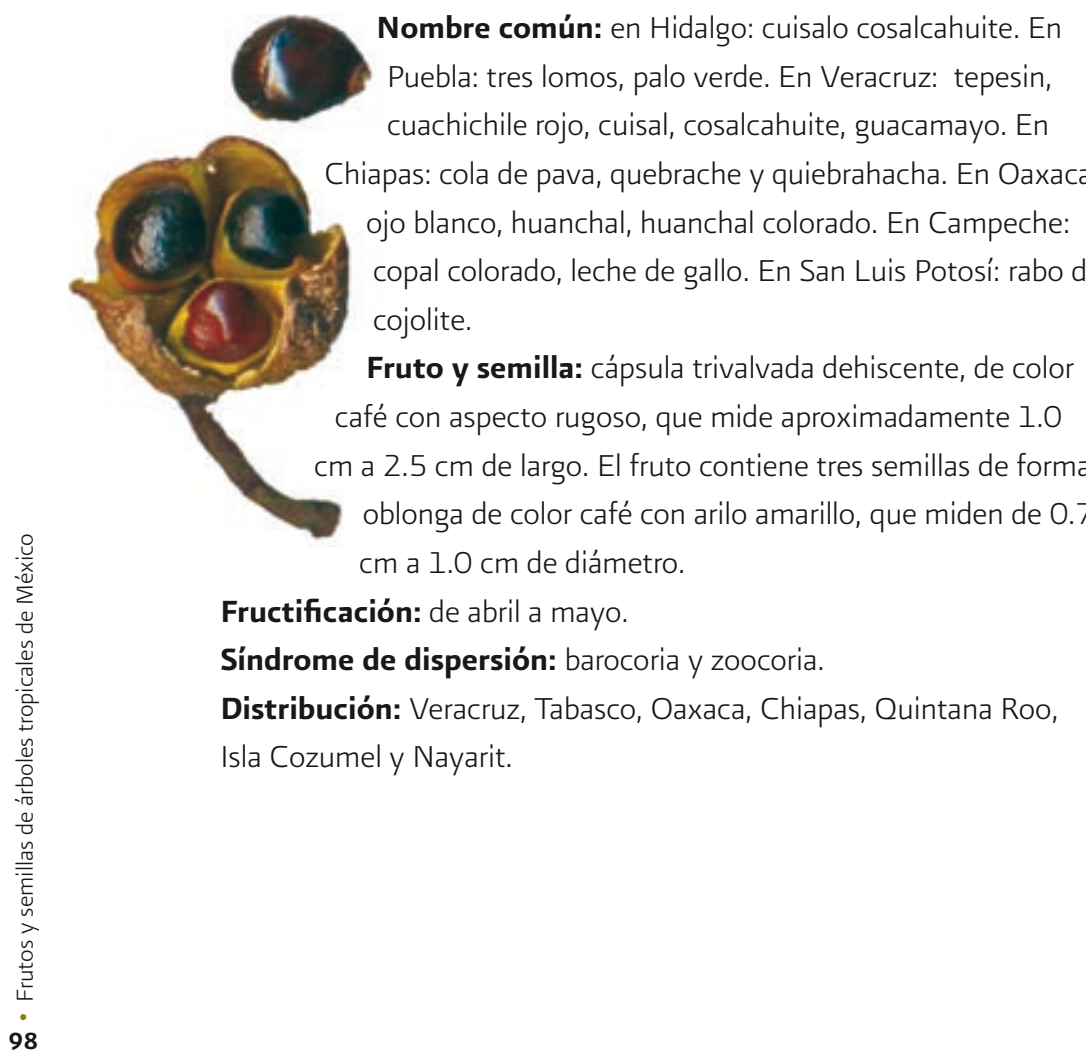




\section{Cupania macrophylla A.Rich. Sapindaceae}

Fruto y semilla: cápsula dehiscente trilocular, de color verde en forma de rehilete, cuya altura es de $1.5 \mathrm{~cm}$ a $2 \mathrm{~cm}$. Cada lóculo mide $0.4 \mathrm{~cm}$ de ancho por $0.6 \mathrm{~cm}$ de largo. Contiene tres semillas globosas de $0.3 \mathrm{~cm}$ de diámetro, que al madurar son de color rojizo, con arilo de color verde en la parte basal.

Fructificación: de junio a octubre.

\section{Síndrome de dispersión:}

barocoria y socorría.

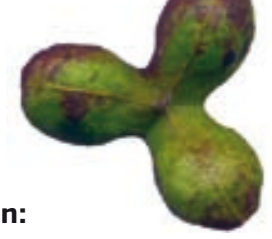

Distribución: Tabasco y Chiapas.
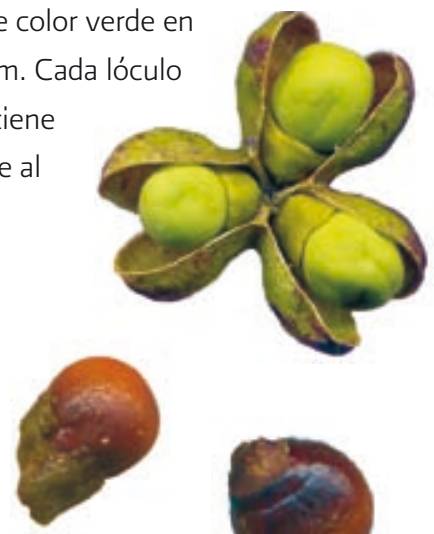


\section{Sapindus saponaria L. Sapindaceae}

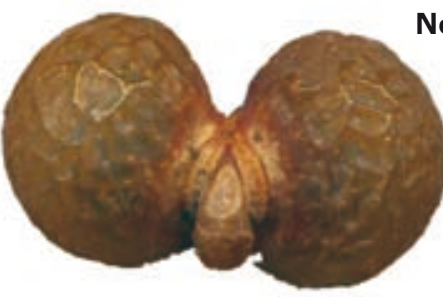

Nombre común: jaboncillo, palo blanco y amole. Fruto y semilla: bayas indehiscentes en grupos de 2 o 3, que miden aproximadamente $1.8 \mathrm{~cm}$ de diámetro, con forma globosa y superficie arrugada. El fruto es translúcido de color amarillo y contiene en su interior un liquido de consistencia mucilaginosa y transparente. Cada baya tiene una semilla esférica de color negro, de $0.9 \mathrm{~cm}$ de diámetro con uno de sus polos aplanado.

Fructificación: de enero a septiembre. Síndrome de dispersión: barocoria. Distribución: se la encuentra en toda la vertiente del Golfo de México y del Pacífico, y en el norte del país, en los estados de Sonora, Chihuahua, Nuevo León y Tamaulipas. 


\section{Pouteria campechiana (H.B.K.) Baehni Sapotaceae}

Nombre común: en Chiapas: mamey de Campeche. En Veracruz: caca de niño, zapote mante. En Chiapas, Campeche, Yucatán y Quintana Roo: kanixté.

Fruto y semilla: baya de forma globosa de color amarillo verdoso a café cuando madura, de $4.5 \mathrm{~cm}$ a $5.5 \mathrm{~cm}$ de diámetro. Contiene 2 a 5 semillas de $2 \mathrm{~cm}$ de diámetro de forma ovoide, de color café brillante, con una gran cicatriz de color blanco que cubre la mitad de la semilla.

Fructificación: de mayo a octubre.

Síndrome de dispersión: zoocoria y barocoria

Distribución: En el Golfo de México, San Luis Potosí, Puebla, Veracruz, Tabasco, Quintana Roo y Yucatán. Por la vertiente del Pacífico, desde Nayarit hasta Chiapas.
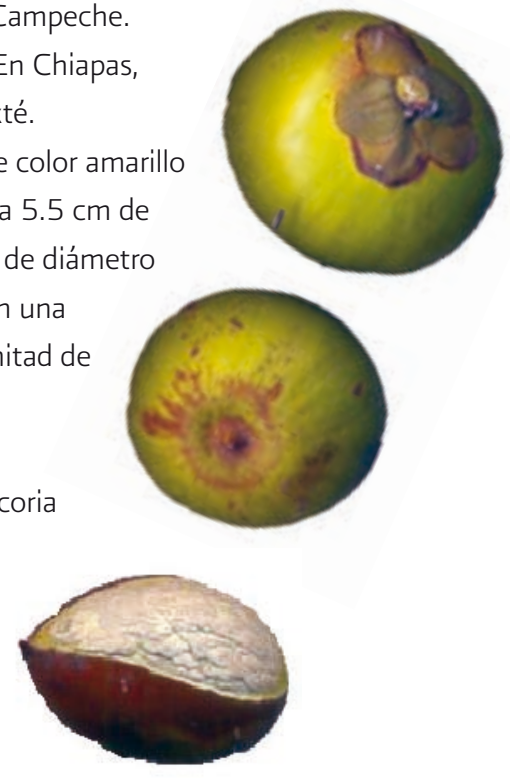


\section{Pouteria sapota (Jacq.) H.E. Moore \& Stearn Sapotaceae}

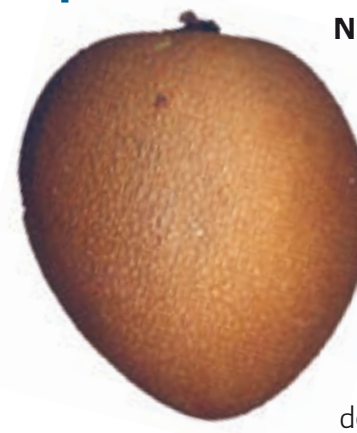

Nombre común: mamey, zapote mamey y mamey colorado.

Fruto y semilla: baya de hasta $16 \mathrm{~cm}$ de largo por $8.5 \mathrm{~cm}$ de diámetro de color café rojizo. El fruto presenta pequeñas escamas que le dan una textura áspera. El fruto es de color café, muy carnoso y comestible. Por lo general, contiene una semilla que llega a medir hasta $10 \mathrm{~cm}$ de largo, de forma elipsoide, con testa leñosa y de color café oscuro, brillante y presenta una cicatriz grande de color

blanco.

Fructificación: de mayo a agosto.

Síndrome de dispersión: zoocoria y barocoria.

Distribución: Veracruz, San Luis Potosí, Yucatán, Michoacán, Guerrero y Oaxaca. 


\section{Guazuma ulmifolia Lam. Sterculiaceae}

Nombre común: guácima o guácimo.

Fruto y semilla: cápsula ovoide indehiscente de 2.5 a 4 $\mathrm{cm}$ de largo por 2 a $3 \mathrm{~cm}$ de ancho, de color oscuro. El fruto, cubierto de numerosas protuberancias de forma piramidal. contiene múltiples semillas de $0.3 \mathrm{~cm}$ de diámetro y es de forma oblonga y color café claro.

Fructificación: casi todo el año, especialmente de septiembre a abril.

Síndrome de dispersión: barocoria.

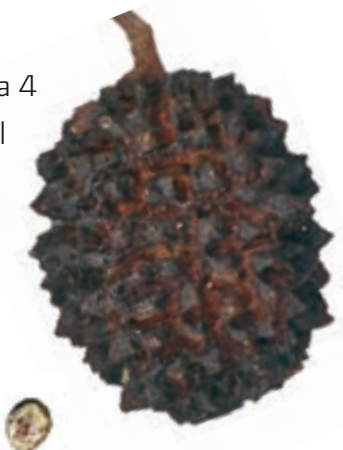

Distribución: por el Golfo de México, se distribuye desde Tamaulipas hasta Yucatán, y por la vertiente del Pacífico, desde Sinaloa hasta Chiapas. 


\section{Heliocarpus appendiculatus Turcz. Tiliaceae}

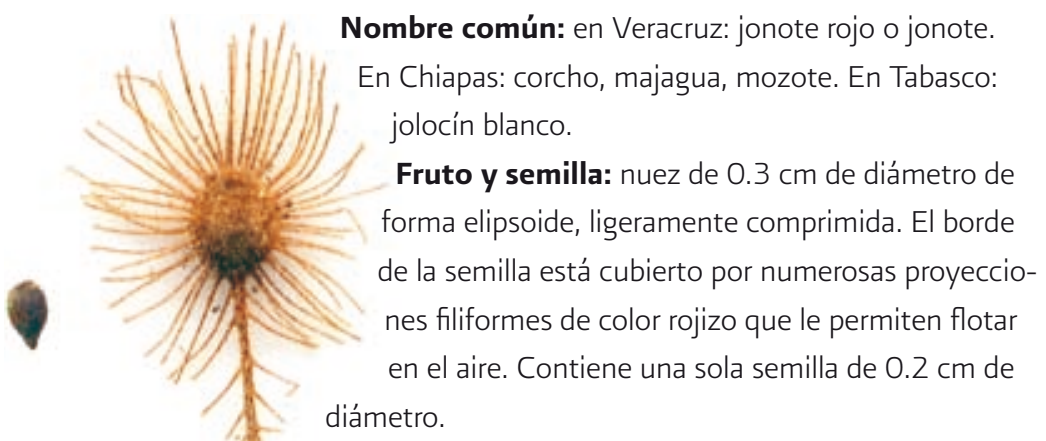

Fructificación: de febrero a mayo.

Síndrome de dispersión: anemocoria.

Distribución: la Huasteca en San Luis Potosí, Sierra Norte de Puebla, Veracruz (Los Tuxtlas) y norte de Oaxaca y Chiapas. 


\section{Luehea speciosa Willd. Tiliaceae}

Nombre común: en Veracruz, Tabasco, Oaxaca y Campeche: Pepe cacao, tepe cacao. En Chiapas: patastillo. En Yucatán: chakats.

Fruto y semilla: cápsula dehiscente de color café oscuro, con la cubierta pubescente; mide $4.0 \mathrm{~cm}$ de largo y contiene numerosas semillas aladas de color dorado opaco, de $1.5 \mathrm{~cm}$ a 2.5 de largo.

Fructificación: de enero a mayo.

Síndrome de dispersión: anemocoria.

Distribución: Veracruz, Tabasco, Chiapas, Oaxaca y la Península de Yucatá

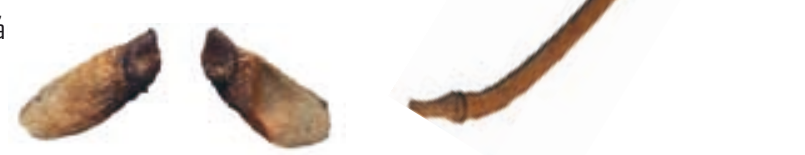




\section{Mortoniodendron guatemalense Standl. \& Steyerm. Tiliaceae}

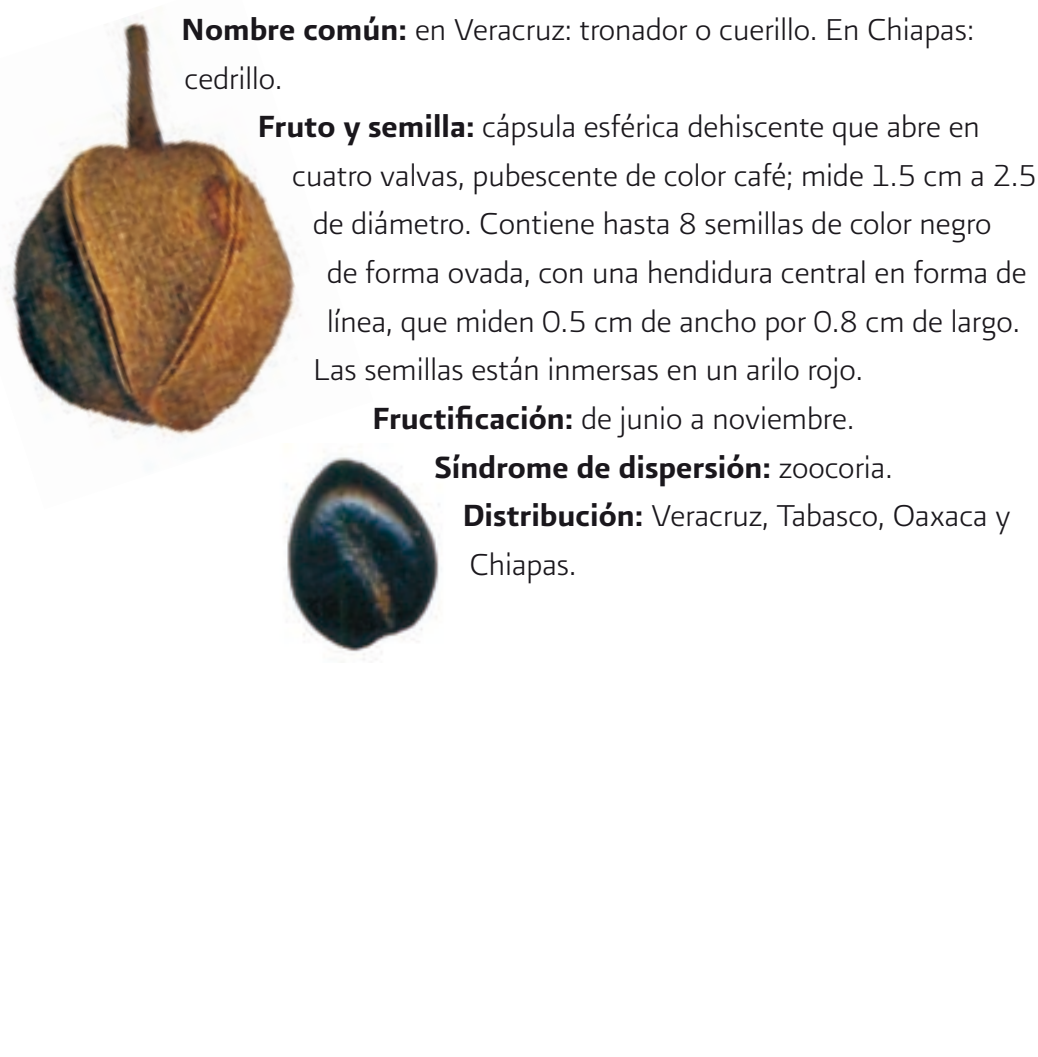




\section{Trichospermum mexicanum (DC.) K. Schum. Tiliaceae}

Nombre común: en Veracruz: guapetate, tepejonote. En Chiapas: corcho colorado, palencano, capulín, majagua y guap tate. En Puebla: tepejonote. En Oaxaca: yaco de cal, yaco de venado, jonote capulín. En Yucatán: holol.

Fruto y semilla: cápsula comprimida, dehiscente y bivalvada, que mide de 2 a $2.5 \mathrm{~cm}$ de ancho por $2 \mathrm{~cm}$ de largo, de color oscuro y pubescente. Las semillas son numerosas, presentan un diámetro de $0.3 \mathrm{~cm}$ y son de color oscuro. Las semillas están provistas de numerosos cilios que les permiten flotar y desplazarse por el aire.

Fructificación: de septiembre a mayo.

Síndrome de dispersión: anemocoria.

Distribución: Sierra Norte de Puebla, San Luís Potosí, Veracruz, Chiapas, Campeche y Quintana Roo. En la vertiente del Pacífico se encuentra desde Nayarit hasta Chiapas.

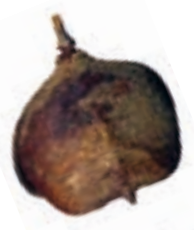




\title{
Ampelocera hottlei (Standl.) Standl. Ulmaceae
}

\author{
Nombre común: en Chiapas y Campeche: luín. En \\ Yucatán: zitsmuk (maya). En Oaxaca; cautivo y \\ frijolillo. En Chiapas: cuerillo. En Veracruz: guaya. \\ Fruto y semilla: drupa de forma ovoide o globosa \\ de color verde, con un diámetro aproximado de 1.5 a \\ $2 \mathrm{~cm}$. El fruto contiene una semilla de forma esférica, \\ cubierta por endorcarpo grueso (hueso) de color pardo, \\ de aproximadamente $0.7 \mathrm{~cm}$ de diámetro. La semilla mide \\ entre $1 \mathrm{~cm}$ a $1.3 \mathrm{~cm}$ de diámetro.
}

Fructificación: de mayo a julio.

Síndrome de dispersión: zoocoria.

Distribución: Oaxaca, Tabasco, Veracruz, Campeche, Chiapas y Yucatán. 


\section{Trema micrantha (L.) Blume Ulmaceae}

Nombre común: capulín o pellejo.

Fruto y semilla: drupa carnosa indehiscente color roja de forma globosa, miden de 0.4 a $0.5 \mathrm{~cm}$ El fruto tiene una sola semilla de $0.1 \mathrm{~cm}$ de diámetro de color negro y de forma globosa con la testa poco arrugada.

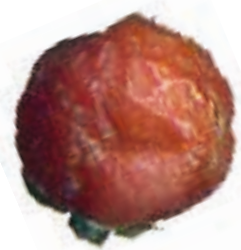

Fructificación: todo el año.

Síndrome de dispersión: zoocoria.

Distribución: por el Golfo de México, desde Tamaulipas hasta Quintana Roo, y por el Pacífico, desde Sonora hasta Chiapas. 


\section{Aegiphila costaricensis Moldenke Verbenaceae}
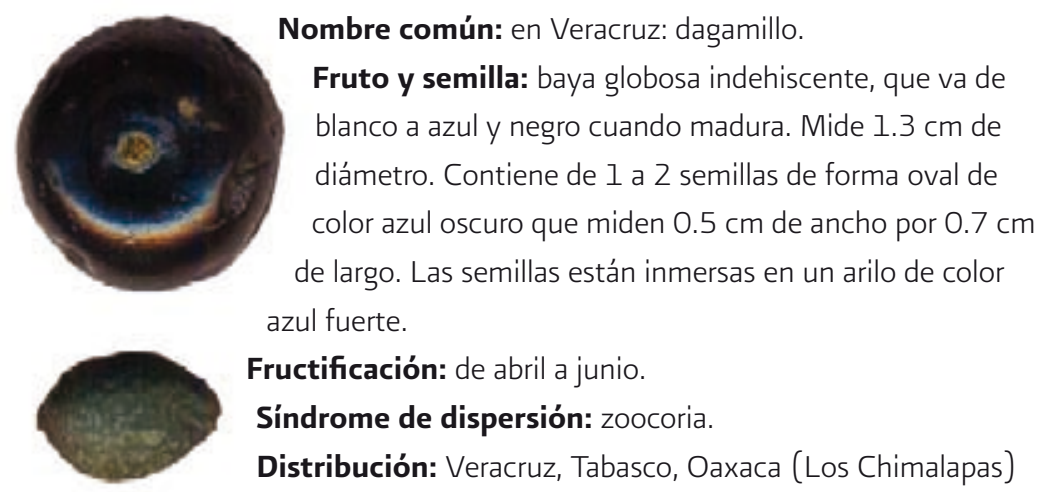

Fructificación: de abril a junio.

Síndrome de dispersión: zoocoria.

Distribución: Veracruz, Tabasco, Oaxaca (Los Chimalapas)

y Chiapas. 


\section{Citharexylum affine D. Don Verbenaceae}

Nombre común: en Veracruz: tres lomos.

Fruto y semilla: baya roja carnosa, de forma oval, de $1.8 \mathrm{~cm}$ de diámetro. Contiene dos semillas de forma oblonga; uno de sus lados es mas plano que el otro. Las semillas son de color crema con una muesca en uno de sus puntas. Miden $0.5 \mathrm{~cm}$ de ancho por 0.7 cm de largo.

Fructificación: de mayo a agosto.

Síndrome de dispersión: zoocoria. Distribución: Veracruz y Chiapas, y por la vertiente del Pacifico: Nayarit, Guerrero, Jalisco y Michoacán.
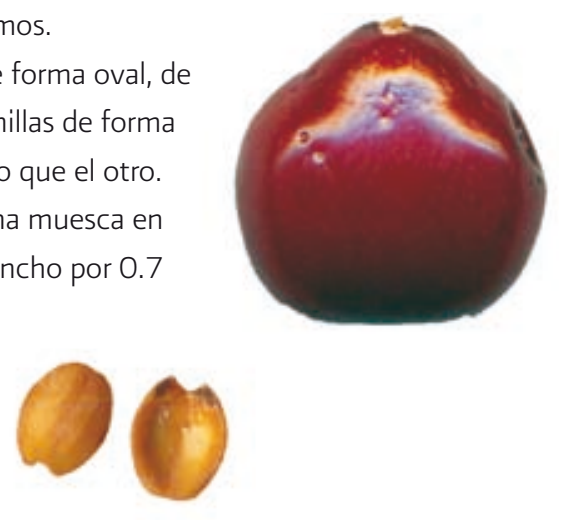


\section{Vochysia guatemalensis Donnell Smith Vochysiaceae}

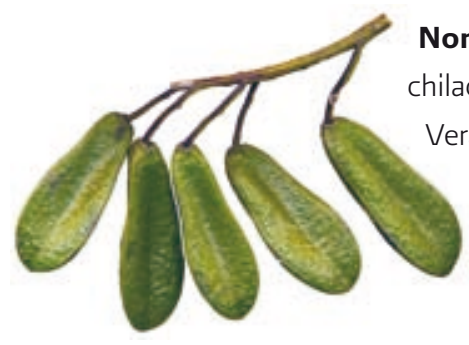

Nombre común: en Chiapas: cozolmeca, chilacayote, maca blanca, San Juan. En Oaxaca y Veracruz: palo de tecolote, corpo, palo de brujo o palo de agua.

Fruto y semilla: cápsula dehiscente que abre en tres valvas y contiene tres semillas. El fruto es de forma oblonga alargada de color verde. Mide aproximadamente de 3.9 a $4 \mathrm{~cm}$ de largo y de ancho entre 1.3 y $1.5 \mathrm{~cm}$ Las semillas son aladas, de color café, y alcanzan, incluyendo el ala, hasta $3.8 \mathrm{~cm}$ de largo por

$0.5 \mathrm{~cm}$ de ancho y $0.3 \mathrm{~cm}$ de grueso.

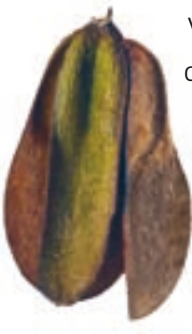
Fructificación: de junio a septiembre. Síndrome de dispersión:

anemocoria.

Distribución: Veracruz, Tabasco, Oaxaca y Chiapas. 
Alado: provisto de un ala.

Anemocoria: dispersión de las diásporas por medio de la fuerza del viento.

Aquenios: fruto seco, pequeño duro e indehiscente, proviene de un único carpelo, con una sola semilla. Ejemplo: Cecropia obtucifolia.

Arilo: nombre que se le da la excrecencia carnosa que se forma en la unión entre el funículo y la semilla. También hace referencia al endocarpio o mesocarpio carnosos, y el arilo puede envolver parcial o totalmente a la semilla. Sirve de alimento para diferentes animales y puede ser de diversos colores Ilamativos. Ejemplos: Stemmadenia donnell-smithii, Swartzia guatemalensis.

Autocoria: dispersión de las diásporas por mecanismos propios, como explosión. Ejemplo: Gliricidia sepium.

Barocoria: dispersión de las diásporas por gravedad.

Baya: fruto con el endocarpio muy delgado y mesocarpio carnoso. Ejemplos: Brosimum alicastrum, Pouteria sapota.

Cápsula: fruto simple que abre cuando está maduro por más de una línea de dehiscencia, puede ser seca o carnosa. Ejemplos: Pachira acuatica, Hampea nutricia.

Cúpula: estructura de forma de copa que cubre parte del fruto. Surge de la base de algunos frutos. Ejemplo: Nectandra ambigens. 
Dehiscentes: fruto que abre. Ejemplos: Erythrina folkersii, Stemmadenia donnell-smithii.

Diáspora: proporción de la planta que se desprende y se dispersa, la cual incluye al fruto y a la semilla.

Drupa: fruto simple con mesocarpio carnoso y endocarpio muy fuerte y leñoso. Ejemplos: Calophyllum brasiliense, Calatola laevigata.

Elíptico: de contorno oval, angosto y redondeado en los extremos y más ancho cerca o en la mitad del fruto.

Endospermo: material de reserva alimenticia que se encuentra dentro de la semilla.

Endocarpio: capa interna del pericarpio.

Esférico: en forma de esfera. Ejemplos: Bursera simaruba, Rochefortia lundellii.

Esquizocarpo: fruto simple indehiscente, con muchas semillas que son formadas cada una por un carpelo. Ejemplo: Robinsonella mirandae. Epicarpio: cubierta exterior del pericarpio.

Fruto: estructura (pericarpio) que protege a la semilla.

Fruto compuesto: fruto (falso) formado por la unión de varios frutos, derivados de varias flores, lo cual da una apariencia de un solo fruto. Ejemplos: Ficus maxima, Poulsenia armata.

Fruto simples: fruto que proviene de un solo ovario. Ejemplos: Brosimun alicastrum y Trophis mexicana.

Funículo: lo que une a la semilla con la pared del fruto.

Folículo: fruto monocarpelar, simple, dehiscente que abre a lo largo de una sutura. Ejemplos: Tabernaemontana alba y Aspidosperma megalocarpon.

Glabro: sin indumentos, lampiño.

Hidrocoria: dispersión de las diásporas por medio de la fuerza del agua. 
Hilio: punto de unión del funículo a la semilla, este puede ser muy evidente como en el caso de las semillas de las Sapotaceas. Ejemplo: Pouteria campechiana.

Hueso: cubierta dura que cubre a la semilla en el interior de algunos frutos, como las drupas. El hueso es el endocarpio lignificado. Ejemplos: Spondias radlkoferi.

Indehiscentes: fruto que no se abre y permanece cerrado. Ejemplos: Hymenaea courbaril, Cynometra retusa.

Lenticela: poro protuberante y alargando que se encuesta en la cortezas de varios tallos leñosos y en varios frutos. Su función es el de intercambio de gases.

Mesocarpio: capa media del pericarpio. Ejemplo: Cedrela odorata.

Mucilaginosa: de consistencia viscosa. Ejemplo: Muntingia calabura.

Nuez: fruto simple indehiscente, normalmente con una semilla, seco y duro. La semilla se encuentra dentro de una cavidad en el interior del fruto. Ejemplos: Cordia alliodora, Heliocarpus appendiculatus.

Oblongo: la forma es ovoide, pero es más largo que ancho. Ejemplo: Nectandra ambigens.

Obovada: de forma ovide, uno de los polos es más amplio que el otro.

Ovoide: en forma de huevo. Ejemplos: Calatola laevigata.

Papiráceo: delgado con la consistencia un poco mas frágil que el papel.

Pericarpio: el conjunto de las tres capas que conforman al fruto: epicarpio (capa externa), mesocarpio (capa intermedia) y endocarpio (capa interna).

Pubescente: provisto de pelo. Ejemplo: Inga vera.

Reniforme: en forma de riñón. Ejemplo: Andira galeottiana.

Rugoso: arrugado. 
Testa: cubierta de la semilla.

Trilobulado: con tres lóbulos. Ejemplo: Croton schiedeanus.

Valva: partes del fruto que se fraccionan y se abren. Ejemplo:

Bernullia flammea.

Sámara: fruto seco provisto de un ala membranosa delgada o gruesa, la cual se extiende o rodea a la semilla. Ejemplo: Pterocarpus rohrii. Samaroide: en forma de sámara.

Semilla: es el resultado de un ovario fecundado maduro que protege al embrión.

Sicono: fruto falso o compuesto formado por la unión de frutos derivados de varias flores pero con la apariencia de uno solo. Ejemplo: Ficus maxima.

Seco: sin arilo. Ejemplo: Cederla odorata.

Vaina: fruto simple que abre a lo largo de una línea de dehiscencia. Zoocoria: dispersión de las diásporas por medio de animales (aves o mamíferos). Ejemplo: Cecropia obtucifolia. 


\section{BIBLIOGRAFÍA}

Breedlove D. E. 1986. Listado florístico de México IV. Flora de Chiapas.

Instituto de Biología, UNAM, México.

Cowan, C. 1978. Listado florístico de México I. Flora de Tabasco.

Instituto de Biología, UNAM, México.

García-Pérez E., J. Meave y C. Gallardo. 2001. Vegetación y flora de la región de Nizanda, Istmo de Tehuantepec, Oaxaca, México. Acta Botánica Mexicana 56: 19-88.

González, E., R. Dirzo y R.C. Vogt. 1997. Historia Natural de Los Tuxtlas,

Veracruz. CONABIO, UNAM, México.

- 1987. Listados Florísticos de México. VII. Estación de Biología

Tropical "Los Tuxtlas" Veracruz. Instituto de Biología, UNAM.

México.

—. 1995. Lista florística comentada de la Estación de Biología

Tropical "Los Tuxtlas" Veracruz. México. Revista de Biología Tropical 43:75-115.

_. 1996. Estación de Biología Tropical "Los Tuxtlas" Veracruz.

México: lista florística comentada (Mimosaceae a Verbenaceae).

Revista de Biología Tropical 44:41-59.

Informe final. 2004. Vegetación y flora del Rancho Zapotal, municipio de

Tizimin, Yucatán. Pronatura Península de Yucatán, México.

Lorea Hernández Francisco. 2000. Estudio florístico de los bosques

mesófilos de la Sierra Mazateca de Oaxaca. México. Informe final 
Proyecto U028. CONABIO, México.

Lott, E. J. 1985. Listado florístico de Jalisco III. La Estación de Biología,

Chamela. Instituto de Biología, UNAM, México.

Martínez Gordillo, M., J. Jiménez Ramírez, R. Cruz D., E. Juárez A., R.

García, A. Cervantes y R. Mejía. 2002. Los géneros de la familia

Euphorbiaceae en México. Anales del Instituto de Biología, UNAM.

73 (2): 155-281.

Navarro Sigüenza, A. y J. Meave del Castillo. 1996. Inventario general de la flora y fauna de la región de los Chimalapas, Estado de Oaxaca. Informe Final Proyecto BOOZ. CONABIO. México.

Ochoa-Gaona, S. y V. de la Cruz-Arias. 2002. La distribución y fonología de la flora arbórea del estado de Tabasco con base en la información de Herbario. Universidad y Ciencia 18(36): 14.

CONANP. 2006. Reserva de la Biosfera de Los Tuxtlas Veracruz.

Programa de Conservación y Manejo (Borrador). Comisión Nacional de Áreas Naturales Protegidas, México.

Pennington T. D. y J. Sarukhán. 2005. Árboles Tropicales de México.

Tercera edición. Ediciones Científicas Universitarias. México.

Rzedowsky, J. 1978. Vegetación de México. Limusa, México.

Sanchez-Garfias, B., G. Ibarra-Manríquez y L. González-García. 1991.

Manual de identificación de frutos y semillas anemocoros de árboles y lianas de la estación "Los Tuxtlas" Veracruz, México. Cuadernos

12, Instituto de Biología. Universidad Nacional Autónoma de México, México.

Schultz, G. P. 2001. Vegetation and floristics of the El Edén Ecological

Reserve, Quintana Roo, México. Ph. D.Thesis. University of

California, Riverside, EUA.

Secretaría de Medio Ambiente, Recursos Naturales y Pesca. 1987. Aviso. 
reserva de la Biosfera, la región conocida como Sierra de Manantlán, ubicada en los municipios de Autlán, Cuautitlán, Casimiro Castillo, Tolimán, y Tuxcacuesco en el estado de Jalisco y Colima.

Sousa, S., M. 1993. Género Inga (Leguminosae: Mimosoideae) del Sur de Mexico y Centroamérica. Estudio previo para la flora mesoamericana. Annals of the Missouri Botanical Garden 80(1): 223-269.

— y E. Cabrera. 1983. Listado florístico de México II. Flora de Quintana Roo. Instituto de Biología, UNAM, México.

Schultz, G.P . 2003. Structure and floristics of the forests at the El Edén Ecological Reserve, Quintana Roo, México. En: The Lowland Maya Area. Three Millennia at the Human-Wildland Interfase. Haworth Press, Inc. New York, Londres,Oxford. Pp. 91-114. Valdez Téllez O., F. Franco, M. Rodríguez, G. Flores, R. Rodríguez, S. Hernández, D. Mariani e I. Calzada. 1995. Listado florístico de México XII. Flora de la reserva Ecológica Sierra de San Juan, Nayarit. Instituto de Biología, UNAM. México. 
Frutos y semillas de árboles tropicales de México, de Jorge Rodríguez Velázquez, Praxedis Sinaca Colín y Gilberto Jamangapé García se terminó de imprimir y encuadernar en los talleres de Impresora y

Encuadernadora Progreso, S.A. de C.V. (IEPSA), Calzada de San Lorenzo 244, 09830, México, D.F., durante el mes de marzo de 2009

La coordinación editorial y la composición tipográfica estuvieron a cargo de la Dirección de Publicaciones del INE

Se tiraron $X X X$ ejemplares 